\title{
Issues in the
}

Commercialization of Magnetic Fusion Power
A. D. Rockwood
T. L. Willke
P. Sommers
M. Selvin

December 1979

Prepared for the U.S. Department of Energy under Contract EY-76-C-06-1830

Pacific Northwest Laboratory Operated for the U.S. Department of Energy by Battelle Memorial Institute 


\title{
NOTICE
}

This report was prepared as an account of work sponsored by the United States Government. Neither the United States nor the Department of Energy, nor any of their employees, nor any of their contractors, subcontractors, or their employees, makes any warranty, express or implied, or assumes any legal liability or responsibility for the accuracy, completeness or usefulness of any information, apparatus, product or process disclosed, or represents that its use would not infringe privately owned rights.

The views, opinions and conclusions contained in this report are those of the contractor and do not necessarily represent those of the United States Government or the United States Department of Energy.

\author{
PACIFIC NORTHWEST LABORATORY \\ operated by \\ BATTELLE \\ for the \\ UNITED STATES DEPARTMENT OF ENERGY \\ Under Contract EY-76-C-06-1830
}

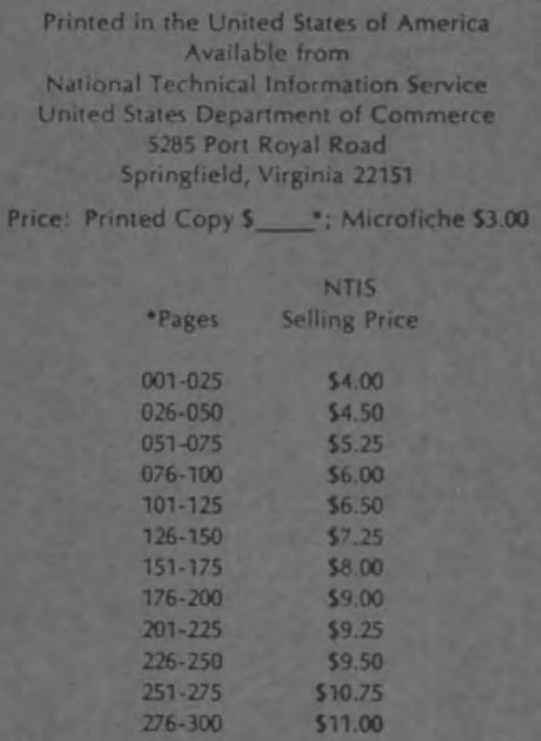




\title{
33679000544355
}

ISSUES IN THE COMMERCIALIZATION OF MAGNETIC FUSION POWER

\author{
A. D. Rockwood \\ T. L. Willke \\ with the assistance of \\ P. Sommers $(a)$ \\ M. SeTvin(a)
}

December 1979

Prepared for

The Office of Fusion Energy

U.S. Department of Energy under Contract EY-76-C-06-1830

Pacific Northwest Laboratory

Richland, Washington 99352

(a) Battelle, Human Affairs Research Centers, Seattle, WA. 



\section{TABLE OF CONTENTS}

1. INTRODUCTION

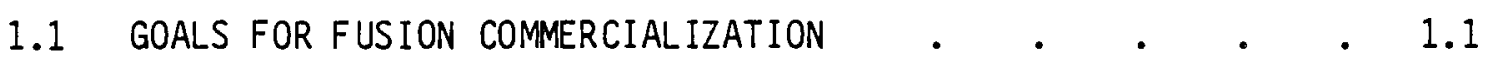
1.2 COMPARISON WITH NUCLEAR POWER $. \quad . \quad . \quad . \quad . \quad . \quad . \quad 1.3$

1.3 BARRIERS TO COMMERCIALIZATION

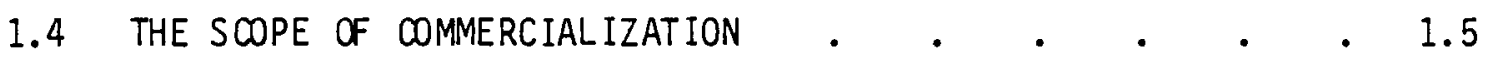

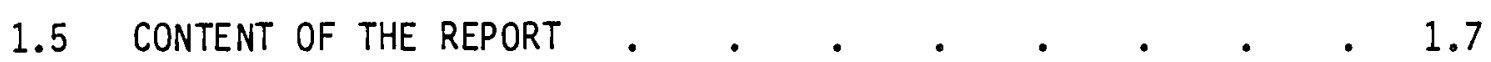

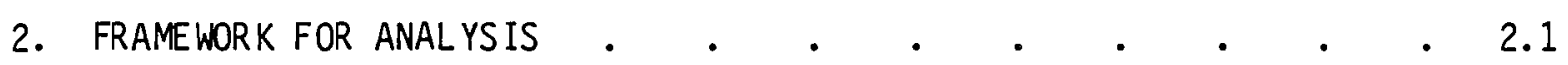

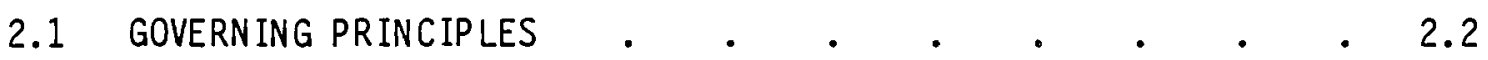

2.2 CONCEPTUAL MODEL OF THE COMMERCIALIZATION PROCESS.$\quad \cdot \quad 2.3$

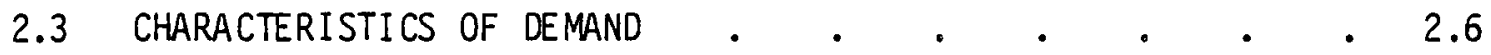

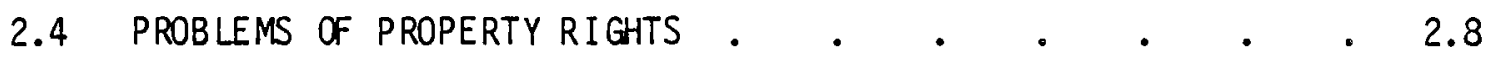

2.5 CAPACITY-TO-PRODUCE . . . . . . . . . 2.10

2.6 PRODUCT CHARACTERISTICS . . . . . . . . . . . 2.11

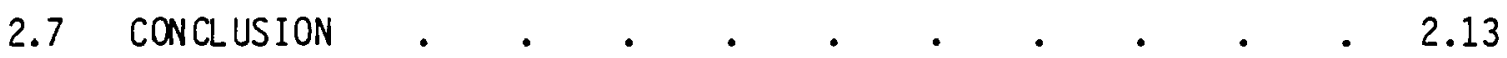

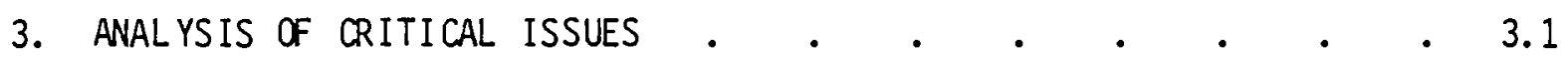

3.1 NATIONAL NEED AND THE ROLE OF FUSION

3.2 PUBLIC PERCEPTION OF FUSION POWER ..$\quad \cdot \quad \cdot \quad \cdot \quad \cdot \quad \cdot 3.3$

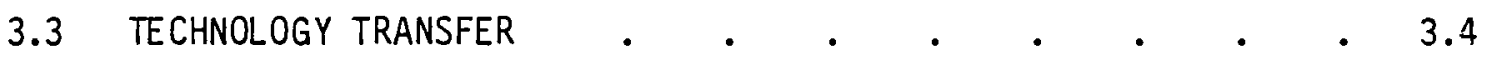

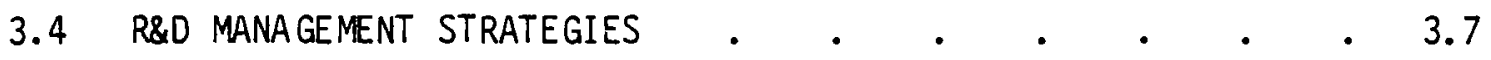

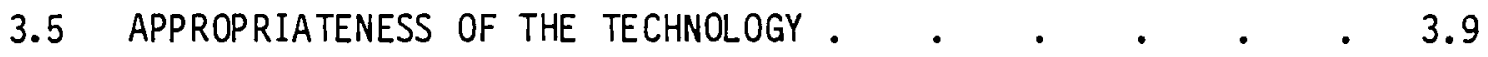

3.6 EXTRA MARKET CONSIDERATONS • . . . . . . . 3.10

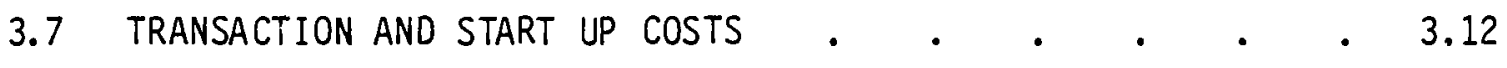


3.8 INDUSTRIAL CHARACTERISTICS - UTILITIES AND

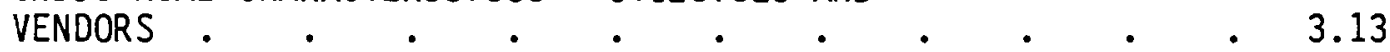

3.9 QUESTIONS OF PROPERTY RIGHTS . . . . . . . . . 3.15

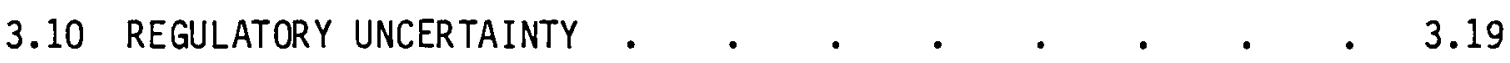

4. COMMERCIALIZATION OF LARGE-SCALE TECHNOLOGIES:

RECOMMENDATIONS FROM THE LITERATURE.$\quad \cdot \quad \cdot \quad \cdot \quad \cdot \quad \cdot 4.1$

4.1 POLICY STUDIES $\quad . \quad \ldots \quad$ •

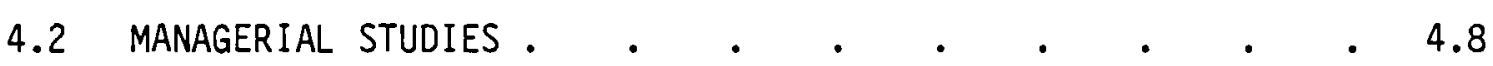

4.3 ECONOMICS STUDIES . . . . . . . . . . . . . 4.11

Diffusion of Innovations . . . . . . . . 4.12

Technology Transfer . . . . . . . . . . 4.14

The Implications of Market and Firm Structure

for Commercialization . . . . . . . . 4.15

4.4 COMMERCIALIZATION OF LARGE-SCALE TECHNOLOGIES $• \quad . \quad$. 4.19

4.5 LARGE-SCALE TECHNOLOGY AND THE ELECTRIC
POWER INDUSTRY $. . \quad . \quad . \quad . \quad . \quad . \quad . \quad 4.22$

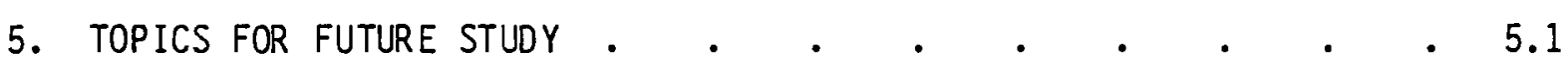

5.1 PUBLIC PERCEPTION OF FUSION •

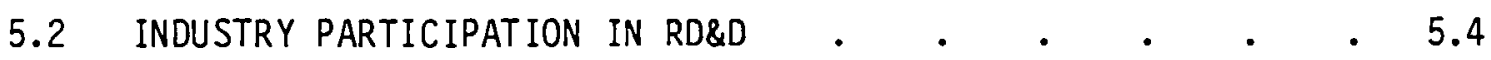

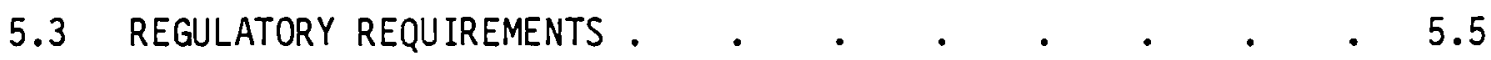

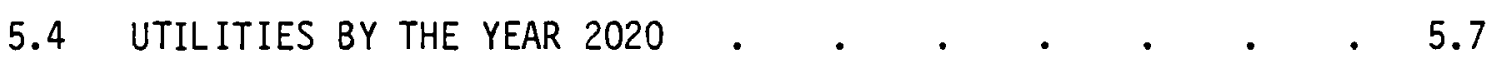

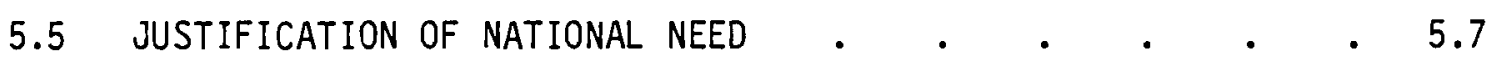

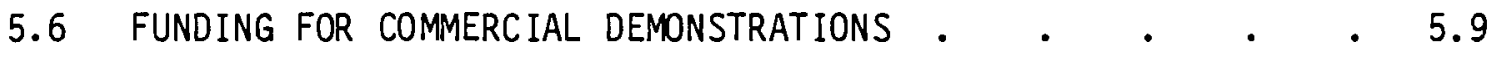

5.7 JOINT PLANNING WITH INDUSTRY . $. \quad . \quad . \quad . \quad . \quad . \quad 5.10$

5.8 FUNCTION OF INDUSTRIAL CONTRACTORS $\quad . \quad \cdots \quad . \quad . \quad . \quad 5.11$

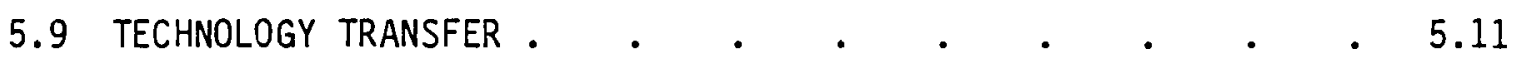

6. BIBLIOGRAPHY 


\section{INTRODUCTION}

For more than a quarter of a century, controlled thermonuclear reactions, or fusion, have held forth the promise of unlimited energy supplies to replace the dwindling resources of fossil fuels. That promise is now within reach. During the next several years, the scientific principles of magnetically confined fusion will be proven and its application to the production of energy can proceed. Technically, the application of fusion--its engineering, development, and integration with the components of a working $p l$ ant--will be ever as difficult as the proof of scientific feasibility. The fusion effort will require most of the next twenty-five years before fusion can be used on a practical level.

Camercialization is evident at the point in time when the government concludes its effort and industry takes over. Commercialization, however, is not an event; it is a process that begins with the commitment to develop a technology and ends when the environment for its widespread application has stabilized. With fusion approaching the milestone of scientific feasibility, attention is being directed towards the problems of engineering development. As difficult as that may be, the corollary tasks of commercializing fusion are equally difficult. The problems are complex and ill-defined; they require attention to the socioeconomic as well as technical concerns. The purpose of this study is to identify and outline the issues that must be considered if fusion is to be put into commercial practice. We seek to put the issues into perspective around a consistent framework and to recommend a program of study and research to anticipate and handle the issues for a successful fusion commercialization program.

\subsection{GOALS FOR FUSION COMMERCIAL IZATION}

Fusion differs from most other new energy technologies in that it has been solely derived from research and development funded by the federal government while the product will not be used primarily by the government. Nuclear power offers the only significant parallel to fusion. The government 
has taken the responsibility not only to prove the basic concept but to pursue the development through the initial phases of commercial demonstration and use. The duration and cost of the fusion research and development program is unparalleled. Research has been pursued for over 25 years in an effort to understand and control the process in the laboratory. Scientific feasibility is not yet universally acknowledged, al though experiments under construction are likely to be conclusive. Another 25 years may be needed before the first commercial reactor demonstration $\mathrm{plant}$ goes on 1 ine. It seems unlikely, given current knowledge and projections, that significant plant capacity will be available before 2020, a period of nearly 50 years from the initiation of research to significant use.

The government is promoting and supporting technological change to achieve the long-term goals of national security, economic strength, and general well-being for its people. It has established programs to improve productivity, prompt economic growth, and create a posture of technological strength in international competition. The role of government is expanding because of the conclusion that market forces alone are not sufficient to achieve these national objectives. Three specific reasons are advanced for government intervention in the process of technological change. First, private firms are unable to capture all of the benefits arising from technological developments, and thus they tend to underinvest in programs of national importance. While the costs of private development are incurred only by the sponsoring firm, the benefits accrue to society at 1 arge. Second, the size of most firms prohibits their investment in large-scale, high-risk development programs. Third, government intervention is needed to ensure the public interest. Industry is structured to respond to the demands of the market and is ill-equipped to respond to national priorities (Holloman 1979).

Comercialization implies a transfer of publicly developed technology to the private sector for production and operation. If the process is to be successful, it must be integrated with the engineering development process. The entire program must be oriented and directed toward the needs of the public and the requirements of the market at the time of introduction. Users 
must recognize the need for the technology, and the potential market must be 1 arge enough to justify the investments in producing and maintaining the technology. The technology must fit reasonably well into the existing industrial . and utility infrastructure and must be compatible with current and potential regulat ory constraints. Last, the public must accept the technology based upon accurate perceptions of its potential for both public benefit and adverse impact.

\subsection{COMPARISON WITH NUCLEAR POWER}

The commercialization of the light water reactor (LWR) is a convenient model for fusion because of outward similarities in the application of the technology. Both are capital intensive and centralize the production of power. Physical processes and economies of scale tend to promote plants 1 arger than their nearest competitors. Both require(d) funding and a long period of development, which the government could provide. There is much to admire about the LWR experience. It proceeded in successive stages from engineering experiments to ever 1 arger commercial demonstration plants. Industry, aided by the utilities, played a vital and aggressive role in putting nuclear power into practice. It also had some advantages that are not completely available in the current environment for fusion. It was pursued with single-minded purpose by an agency with a clear mandate to promote its development and commercial use--the Atomic Energy Camission. Congress put its considerable weight behind nuclear power development through the Joint Camittee on Atanic Energy. Moreover, industry assumed the business risks and burdens of building the first series of commerical plants.

The experience of nuclear power is not likely to be repeated for fusion or any other 1 arge-scale technology, if only because the social climate has changed dramatically over the last two decades. For fusion there is no large and corollary program, such as the naval reactor program, that can provide experience and broad understanding in the areas of reactor design, technology, and operation, to say nothing of the momentum imparted to the civilian reactor program. Industry appears to be less willing to make long-range investments 
in the program, recognizing the substantial safety and environmental premium that must be paid to convert a technology from the demonstration phase to a profit-making enterprise. Unlike fission, the scale of fusion experiments precludes the 1 arge number of reactor concepts and even multiple reactors of a single concept enjoyed by the fission program. Last, fusion will be introduced into an econamy of a mature LWR, and possibly liquid metal fast breeder reactor (LMFBR), industry, where initially it may not be economically competitive (Nemzek 1974)

\subsection{BARRIERS TO COMMERCIALIZATION}

In the opinion of one analyst, government regulation probably presents the greatest barrier to the introduction and use of new technologies, so industry tends to look for solutions that offer the least institutional resistance rather than offer the greatest public (and private) benefit (Linden 1978). Until there is an improvement in the general climate in which energy industries function, correcting the deficiencies at the interfaces of government and industry will not be very productive. There is an urgent need for regulatory and legislative stability in energy, economic, and environmental matters. Uncertainities in these areas of public policy are perhaps the greatest deterrent to the commercialization of new energy technologies. While the fusion program cannot hope to cope with problems of this magnitude, an understanding of the problems is important to the creation of viable fusion strategies.

Linden (1978) states that the government's "massive and still increasing involvement in energy research, development, and demonstration (RD\&D) has a negative impact on the climate for commercialization for the following reasons.

1) Economic benefits derived from a proprietary position are reduced or eliminated.

2) Financial returns, both near - and long-term, tend to be low for technical innovations made either in part or totally with public $f$ unds because of the pressures of public policy. 
3) There is no technical infrastructure under the control of industry to continue the development of or to trouble-shoot new technology developed by the government.

4) As a result of the negative impact of 1,2, and 3 above, the capital markets tend to resist private investment in new energy technologies developed under government auspices or, more generally, introduced from a source with questionable capability in lending long-term technological support."

Although the eventual total cost of fusion R\&D will be high, it is still a low-cost investment when compared with the cost of translating the technology into a competitive commercial product. For industry to make that investment, they must be able to convert the investment into a private return that equals or exceeds other investment opportunities. Specifically, there are at least four critical prerequisities for the timely commercialization of a high-risk, capital-intensive technology like fusion. First, there must be a sizable economic incentive on the basis of existing or expected conditions. Second, there must be a high probability of a reasonable return on investment, as viewed by the investor. Third, these must be an adequate supply of capital. Fourth, the government must provide technical support to solve problems associated with its introduction and use.

\subsection{THE SCOPE OF COMMERCIALIZATION}

The Department of Energy (DOE), the National Aeronautics and Space Adninistration, the Department of Transportation, and several other federal agencies and commissions are all involved in commercializing technologies. Within DOE, Assistant Secretaries for Resource Applications and Conservation and Sol ar Applications were established to facilitate cormercialization. Despite, or perhaps because of, wide-ranging government interest in the subject, there is no standard, widely accepted definition of cormercialization. Successful R\&D programs often result in the trial of a concept at the experimental or pilot-plant level. After the successful operation of the plant, the next step is usually the construction and operation of a full-scale plant, which produces for a market on a commercial basis. Some authors have defined 
commercialization as putting this first full-scale comercial demonstration into operation (Mansfield 1977 and Teece 1977). This notion is derived in part from the philosophy that the government's role in the process ends with a demonstration plant. It is expected that industry will make the necessary investments to put the technology into wi despread use through the operations of the market.

The government in this country does not, with some exceptions, act as a supplier of economic goods. The production and sale of goods is the job of private enterprise in our economic system. Hence, when the government sees a reason to support $R \& D$ in some area and when it subsequently announces that it wants to commercialize the R\&D product, the implication is that the knowledge created by or with government support is to be transferred to private-sector firms, who will then employ this knowledge to produce goods for sale in the marketplace. Without some sort of government comercialization program, there is an implied danger that this transfer of technological knowledge will not take place. Therefore, technology transfer from government to the private sector is a crucial aspect of commercialization.

The government plays a significant role in our economic system through a 1 arge body of regulatory agencies. Now, more than ever before in our history, the government determines what goods are available through the market, controls the type and extent of transactions, and places limits on the rights of industry. In some respects, it is easier for industry to develop and commercialize its own innovations than to adopt technologies developed largely by the government. Since the goverment has such a dominant influence on the adoption of new technologies--even technologies that are shown to be in the public interest, the government's responsibility now extends beyond the demonstration of proof-of-concept. The proper objective for government in commercializing a new technology is to create a milieu for industry to adopt the technology on its own. Incentives must be created that relate to the interests of industry in making business investments while, at the same time, fostering competition.

An expanded concept of commercialization encompasses the entire process leading to the first full-scale plant and extends beyond this point to include 
the diffusion process by which the new product or process spreads from firm to firm within an entire industry. The Massechusetts Institute of Technology (MIT) Energy Laboratory (1976) defines commercialization as a process having four phases: invention, development, introduction, and diffusion. Cormercialization is defined here as the entire economic process of getting a new product or process developed by or for the government, transferring the product or process to potential vendors and users, and insuring it wide-spread use in the marketplace. This definition encompasses the expanded notion of commercialization from invention through diffusion. Conceptual frameworks, the determinants of success; explanations of the pattern and rate of adoption; and strategies for managing innovation processes are all relevant topics that need to be considered.

\subsection{CONTENT OF THE REPORT}

If fusion technology is to benefit society through its adoption and use by the U.S., then a commercialization program must be designed that complements the technology development program. The purpose of this study is to provide information and analysis to develop:

1) A strategy for the timely commercialization of fusion power plants within the context of the fusion development program;

2) A broad understanding of the commercialization process as it relates to the adoption of capital-intensive, high-technology energy systems such as fusion power plants;

3) Knowledge of the barriers to commercialization and policy options to deal with them; and

4) Insights into the interrel ationships between R\&D program management and commercialization planning.

In Section 2, a framework for analysis is presented around which the issues of commercialization and the available policy options can be structured. The model suggests four essentials if commercialization is to succeed: market demand, a capacity to produce the technology, attributes of the technology appropriate to the production and using sectors of the economy, 
and an institutional framework that allows and supports the adoption of the technology. In Section 3, the four elements of the model are used to identify the issues relevant to the commercialization of magnetic fusion power. Some of the issues present special problems for fusion while others have been extensively studied in relation to other commercialization efforts and need only be interpreted for the fusion program. In Section 4 , the literature on cormercializing large-scale technologies is reviewed and recomendations are made on the need for further study. In this survey, comercialization is examined from the perspectives of policy, the management of R\&D, economic theory, the particular problems of commercializing large-scale technologies, and the adoption of these technologies by the electric utilities. In Section 5, nine topic areas are suggested for study. Each of the topics is related to decisions in the fusion program that are to be made in the near future. 


\section{FRAMEWORK FOR ANALYS IS}

Questions related to the process of commercialization should proceed from the extensive discussion of the rationale for federal involvement in energyrel ated research and development. (a) If a new technology is shown to provide benefits to the nation that exceed its costs, both economic and social, then its development can be justified. The development of the technology creates a corollary obligation: provide for its commercialization. This is not the same as forcing a technology into the marketplace; rather, development should be managed to meet the needs of the market, including the removal of potential barriers to the market's development. Failure to do so will result in frustration of the commercialization process. After determining that an emerging technology will provide significant benefits to the nation, it is important to $\mathrm{pl}$ an actions for obtaining these benefits.

A technology's direct cost of production relative to competing technologies is one factor among many that contribute to market acceptance. For a major innovation like fusion, it is more a matter of market development than merely the acceptance of the concept. This process of market development for 1 arge-scale innovations has become known as commercialization. Commercialization is essentially the interaction of factors that contribute to the demand for the technology with those that affect its supply. The process of assimilating a new technology is more than adapting a concept to the particular needs of the present day economy; basic structural changes can result from the adoption of a new production technology. Both the supply sector and the demand sector are likely to be altered. In assessing the feasibility of a technological innovation, the nature of the probable changes should be considered.

(a) For a further discussion of the rationale for federal involvement in energy-rel ated R\&D, refer to Holloman (1975). 


\subsection{GOVERNING PRINCIPLES}

The evolution of a new technology toward wi despread utilization by society is often described as a process of stages. The technology is presumed to have passed through a given stage when it passes the sequential tests of scientific feasibility, engineering feasibility, and comercial feasibility. The process and responsibility for a technical development is supposed to be complete when the first commercial-scale prototype is successfully demonstrated. The sequential perspective on this process is dominated by events in the development of the technology and often leads to the association of commercial production with successful commercialization. The commercialization process must be viewed from a perspective broader than purely technical concerns. Sone of the most serious problems awaiting fusion are of social and institutional origins. Parallel to the technological developments is a process of market development, which is tied to socio-economic as well as technical conditions. All elements of the market mechanism must develop before a new technology can be successfully assimilated into the economy.

In a well-ordered program of development, engineering overlaps science and comercial issues overlap technical concerns. Societal concerns also must be $f$ aced long before commercial issues are resolved. The fusion community must attempt to integrate the problems of commercialization with the problems of technology development. To understand the process of commercialization, we will organize the issues around a framework for analysis. The framework suggests priorities for addressing the issues.

Recent studies of both successful and unsuccessful attempts at commercialization have rather convincingly demonstrated that a number of requirements must be satisfied before a given technology can penetrate the market. First and most important, there must be a market for the technology: the direct user must recognize a need for the technology, the demand must be 1 arge enough to justify its introduction, and the technology must be competitive in terms of both expected cost and risk. Second, the technology must be compatible with the needs of the user; it must not only demonstrate acceptable technical performance, but it must meet the economic, regulatory, and social 
criteria at the time of its introduction. These two requirements place a special burden on the R\&D decision maker to guide the development process so that an acceptable product is produced. Third, property rights must be clearly established or there will be no incentive to produce the technology even in the face of a strong market demand. Property rights can take the forms of patent protection and an institutional framework that confers the right to produce and make a profit. Regulation functions to extend or attenuate private property rights. The fourth and often over looked requirement is that the capacity to produce the technology must be transferred to the producing sectors long before the date of comercial introduction. The transfer of this know-how is fostered by industrial involvement in the engineering and development of a technology. Industrial participants often 'sell' a technology far more effectively than government program managers.

The model of commercialization, as presented here, can help clarify the dynamics of the process, but it does not outline a strategy for accomplishing the objectives of the fusion program. Generalized strategies do not yet exist and must be developed with more experience. To some extent, these strategies must be devised on a case-by-case basis. The comercialization model can help define the issues in fusion development that will determine the necessary scope of the effective strategies.

\subsection{CONCEPTUAL MODEL OF THE COMMERCIALIZATION PROCESS}

Camercialization can be viewed as a multidimensional process composed of four basic elements: market demand, property rights, capacity-to-produce, and technological attributes. A full understanding of commercialization requires an integration of all of these. The primary interrelationships among the elements are shown in Figure 2.1. Camercialization must be viewed as a dynamic process governed by the interaction of the technology within the economic and institutional mechanisms. Market demand represents the consumers of the technology's services while capacity-to-produce represents the supplying sector. The elements of property rights and technological attributes represent the institutional and structural factors that determine the efficacy and efficiency of the market mechanism. 


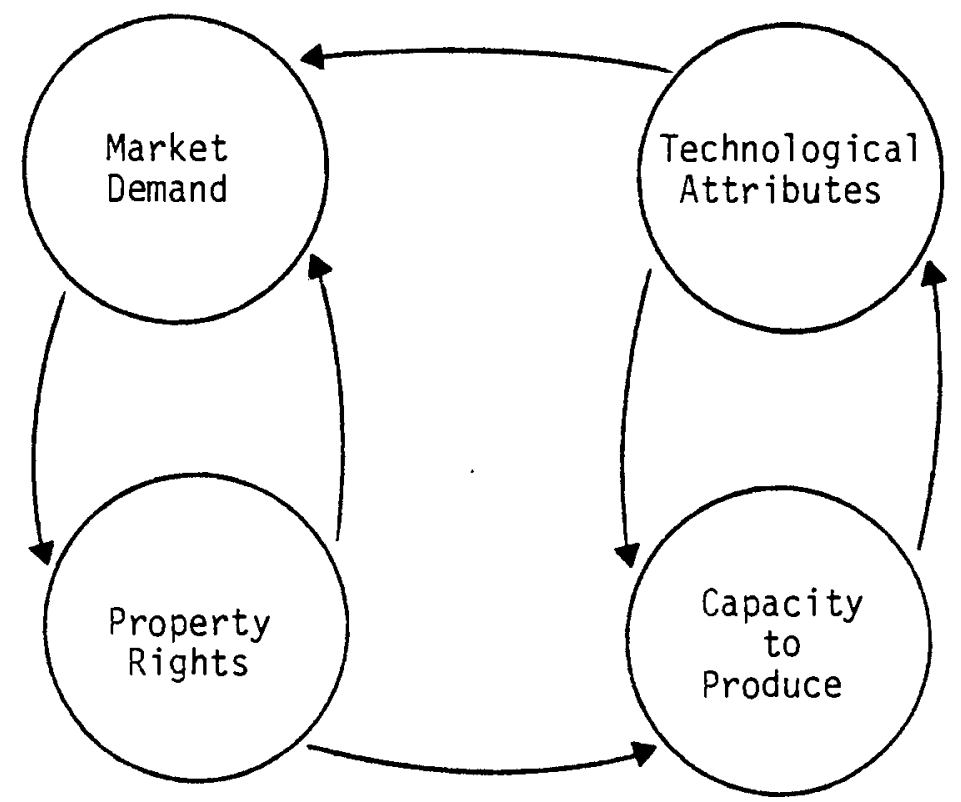

FIGURE 2.1 Conceptual Model of Commercialization

In this conceptual model of commercialization, the logical starting place is the effective market demand. Market demand is derived from the wants and incomes of potential buyers. Commercial acceptance inevitably depends upon the ultimate user's willingness to pay, either directly or indirectly, for an $R \& D$ product through the purchase of some other goods. The element of market demand is a primary component of the theoretical literature on the determinants of technological change (NBER 1962).

Market demand works through the institutional arrangement of property rights to create incentives to produce. For a firm to undertake an investment to develop and produce a new product, the firm must be reasonably assured of recovering its investment. This has been the principal argument for the establishment of patent rights.

The property rights of consumers also influence market demand. Some types of goods, typically known as "public goods," such as the national 
defense, (a) are not subject to the principal of excludability in use. Because individuals cannot be prevented from consuming public goods once they have been produced, consumers will be unwilling to pay private producers of such goods. Since private producers cannot obtain complete compensation for their production, private markets will fail to fully reflect the demand for public goods. Thus, R\&D products with attributes characteristic of public goods may have limited commercial potential unless corrective action is taken by public agencies.

The establishment of incentives-to-produce through the institution of property rights leads to the capacity-to-produce, the third element of the process. Two issues are associated with this element. The first is the problem of technological transfer that has arisen in the context of developed and developing countries but is also relevant to the flow of information between the research and production segments of an economy (Linhares 1976). Technology transfer is central to the commercialization process. In the private sector, research and development tends to be a vertically integrated activity; therefore, the lines of communication between research and production segments are well-established. This link is more difficult to establish when the innovation is being developed in the public sector. The second issue in the capacity-to-produce concerns the behavior of the producing sector and has been addressed in the literature on market structure and innovation (Kamien 1975). Market structure characteristics that convey market power to some firm can influence another firm's decision to enter a new market or adopt a new production technology. Thus, structural characteristics must be considered in the formulation of comercialization policies.

The final element of the comercialization process is the technology's characteristics as they relate both to market demands and to the producing

(a) In the context of energy resources, no technology is a 'pure' public good; however, some have attributes of a public good, for example, proliferation resistant fuel cycles or the security of a domestic fuel supply. 
sector. The attributes of a technology must meet the basic needs of the consuming sector to be commercially viable. In R\&D activities, information on the market demands should be used to guide the development of a new product's characteristics. In addition, attributes of the technology influence the structure of the producing sector, and thus, its conduct and performance. Such features as product differentiation, economies of scale, and economies of scope are important in determining market structure (Scherer 1970).

In the following sections, each of the four elements will be exanined in greater depth and their implications for large-scale energy technologies, principally advanced reactor concepts, will be considered. This framework can be used to identify the salient utility and industrial issues. However, the scope of fusion is such that this will provide only a first glance at the commercialization issues. Several of these issues will merit additional in-depth analyses.

\subsection{CHARACTERISTICS OF DEMAND}

The primary function of any economic system is to satisfy society's wants with the least-cost combination of resources. Thus, the economic concept of demand is determined by the rel ative prices of comodities and the decisionmaker's budget and preferences. The satisfaction of these demands necessitates a set of technologies for producing goods and services with the desired attributes. These requirements establish two principal objectives for new technologies: 1) they must offer a more preferred set of attributes for their cost, or 2) the same attributes must be achieved with fewer resources. In more familiar terms, the first refers to product improvements and the second to cost-reduction innovations.

Recent research on the process of innovation has identified a pattern related to the two principal motives for technical change; it also has interesting implications for the general process of comercialization. Abernathy and Utterback (1978) observed a generic pattern of innovation that begins with new product development. As the tecinnology matures, the thrust of technological change is toward process innovations that help produce the product more efficiently. They also found that new products are of ten the result of efforts 
by small technology-based companies while process innovations are of ten made by the 1 arge manuf acturing firms. They hypothesized that these phenomena are the result of two conditions. First, the cost of change increases with the size and integration of the organization. Second, the user's input into the research process is vital to the success of the innova- tion. Thus, the small organization can be more responsive to the needs of the users since they have more contact with the users and since it is less costly for them to make radical changes in product characteristics. However, as a technology matures and target uncertainties are all but eliminated, the nature of competition tends to shift from product characteristics to price and cost-sharing innovations that are necessary for the organization's survival.

Abernathy and Utterback's findings have potential implications for the course of cormercialization of technologies developed by the federal government. Vendors with substantial interest in producing prevailing products would, at first glance, appear to be the logical producers of the next generation of those products. However, this may not be the case; the cost of change for those organizations may be very significant, due to their specialized knowledge and operating system. Therefore, entry into a broad market with a new technology may come from smaller firms not presently engaged in the market for the prevailing product. As an example, the development and introduction of a high-temperature gas-cooled reactor (HTGR) appears to fit this pattern. A though General A tomic was unsuccessful in its first at tempt to capture a share of the electric generating reactor market with the HTGR, its attempt is noteworthy for other advanced reactor concepts.

The development of a new technology is an investment process and therefore, depends on the function of the capital market. It is often argued that new energy technologies $f$ ail to be privately developed because they cannot attract sufficient capital; thus, government intervention is required. This could either be a problem of insufficient return on the R\&D investment or inability to spread the risks. One could also find a problem of under 
investment in new energy technologies if the social discount rate is less than the private sector's opportunity cost of capital. The private sector decision-makers would discount future benefits more than is socially optimal and thus reduce their investment in long-term R\&D projects. However, this would not be unique to investments in energy-related technologies. There could be a differential impact if energy technologies are significantly more capital intensive or require a longer development period than the typical product. Recent analyses suggest that there is little reason to believe that the capital market creates a significant problem for commercializing new energy technologies (MIT 1976).

\subsection{PROBLEMS OF PROPERTY RIGHTS}

The role of property rights is central to the performance of a market economy. The institutional arrangements of property rights serve as the foundation for exchange relationships between those who demand and those who supply various goods and services (Demsetz 1966 and 1967). An entrepreneur who recognizes the existence of a demand will make the investment (in R\&D and/or capital equipment) necessary to supply the product, provided he can earn a "normal" return on his investment. If the entrepreneur's investment generates benefits external to his operation for which he is unable to obtain compensation, then he will tend to underinvest in that activity. Because information is the output of R\&D investments and because it is very difficult to establish and enforce property rights to information, industry has a tendency to underinvest in research. As previously mentioned, the patent system was adopted to protect the returns of the innovators. Sometimes patents are ineffective or cannot be applied to the given technology; these problems offer another argument for direct public support of innovative activities. It is, however, useful to note that, by statute, DOE does not generally grant contractors the title to patent rights that stem from DOE sponsored research. (a) in other cases, legal protection is unnecessary. What have been termed "first-mover"

(a) DOE may, under certain conditions, waive all or part of their title rights to a contractor's invention. 
effects create market protection for the originator of the product or service. This protection can result from two basic situations; one occurs when brand-name and identification are important in the consumer's purchasing habits while the other occurs when the lead times for another firm to copy, produce, and market a competing product are very long. Due to the complexity of fusion reactor concepts, the second factor could be important. Vendor firms that do not enter the market early may find it difficult to overcome the advantages of experience in design and construction gained by the first firms to develop fusion.

Property rights also influence the demand for products with characteristics of public goods. As previously discussed, without collective action, the demand for public goods will be less than is socially optimal. National defense has long been recognized as a classic example of public goods. The security of a country is a good that can be enjoyed (consumed) by each resident of the country without excluding other residents of the country from the benefit of that good. The value of national defense to society as a whole is the sum of the values to each individual in that country. Since the social value will be greater than the value for any individual or subgroup of individuals, the private sector will have insufficient incentives to invest in national security.

The rights of entrepreneurs are often attenuated by special interest laws and regulations that $c$ an influence the incentives for innovation and create commercialization barriers. For example, entry into the electrical generation industry is controlled by state regulatory commissions. If these commissions are rigid, fusion commercialization could be inhibited. Several characteristics of fusion reactors are likely to result in institutional changes for the users and vendors of the technology. There is some evidence of policy changes at the federal level that could encourage entry into the generation segment of the industry via new technologies. In the National Energy Policy Act, there is a provision for the sales of electricity by nonutilities with cogeneration facilities. Of course, this is a small-scale technology compared to fusion reactors, but this provision could be an important institutional shift. 


\subsection{CAPACITY-TO-PRODUCE}

If the proper incentives for industry investment can be secured through either private property rights or collective action, then we can turn our attention to the decisions of private firms to acquire the necessary capacityto-produce. The capacity-to-produce is acquired by information transfer or, as it is sometimes termed, "technology transfer." The entrepreneur must have both the technical capability to offer a new product or process and realize the potential for economic gain through increased business activity or cost reductions. Many of the risks and uncertainties associated with a technology are reduced as the vendor industry acquires the capacity-to-produce.

Government R\&D managers are key elements of the technology supply industry; as such, they face a conflicting set of incentives. There is a general tendency to model government research management systems after those of the private sector (Eads 1974). Because any decision process will be tied to the nature of the incentive system, it may be difficult, if not self-defeating, to make government R\&D sponsors behave as private firms. The effectiveness of private decision-making is linked to the residual claims on the returns to the firm (Masson 1971). It is impossible to replicate this in the public sector. It is difficult to predict and measure the external benefits from a particular innovation. Therefore, modeling public decision-making after that of the private sector will generate a similar bias against the projects that produce the most external benefits. This is not to suggest that the public sector should be immune from the basic resource allocation rules but rather to point out a fundamental dilema in managing activities that have significant external benefits or characteristics of public goods.

In government-supported research, demonstration projects have of ten been used as vehicles to transfer the technology and to reduce at least the technological uncertainties. The use of demonstration projects can be an important tool in the transfer of federally sponsored research. Demonstration projects with significant early private sector involvement tend to be more successful than those carried longer by the government alone. This, of course, can be 
a chicken-and-egg argument. One could argue that good projects quickly attract private interest or that early private involvement improves the focus of the project. Regardless, the private sector's interest can be an important signal to managers of publicly sponsored R\&D. Demonstration plants both reduce technological risks and disseminate information effectively.

There can be significant financial risks in the construction of the first few commercial-scale plants even after the technology is successfully demonstrated. In the case of fission reactors, the vendors offered purchasers "turnkey" contracts that shifted the financial risks from the purchaser to the vendor. The federal government has sometimes contributed financial support to the first commercial units of a technology. The form in which that support is given will affect the private sector's response. Given that private industry behaves in a risk averse fashion, insuring the purchaser against cost overruns will provide more of an investment incentive than an equivalent dollar amount of fixed sudsidy. A well-designed policy would also require the vendor to share in the overrun risk to ensure cost effectiveness.

The decision of a private firm to acquire the necessary technical capabilities and to enter a new product market will depend on potential variations in product characteristics. Firms that sequentially enter a market tend to offer a product with different attributes than that of existing producers (Prescott 1977). The different attributes afford later firms the greatest opportunity for securing an economic profit. The General Atomic case with the HTGR is again an interesting example. General Atomic, without a prior market position in the electricity generating equipment market, sought entry with a product highly differentiated from the existing producers' thermal electric generators.

\subsection{PRODUCT CHARACTERISTICS}

The attributes that a technology offers the consuming public are the final considerations in the commercialization process. This element is, in many respects, the mirror image of our first factor, market demand. The 
ability of a new technology to meet the requirements of the final users is the last hurdle in the commercialization path. As was observed in Section 2.5, the characteristics offered in a market are determined in part by the structure of the supply sector and the entry decision of competitors. Firms competing in a given market will formulate strategies based upon several par ameters. One of the parameters will be price; the others will include service and specific product attributes.

In a recent analysis of successful corporate innovation policies, Alan Fusfeld (1978) introduced the concept of "technology demand el asticities." This is an extension of the familiar price elasticity concept, which is an index of the sensitivity of the quantity of a product demanded relative to a change in the product's price. Thus, a technology demand elasticity would relate changes in the quantity of a product demanded to changes in the product's characteristics. These el asticities will, of course, vary from market to market. Fusfeld suggested the following generic technological characteristics:

1) Functional Performance - the basic task the device is to perform.

2) Acquisition Cost(a) - the capital cost of the device.

3) Operating cost(a) - the variable cost per unit of service.

4) Ease of Use Characteristics - "the form of the user's interface with the device."

5) Reliability - both normally required service and $r$ andom breakdowns.

6) Serviceability - the speed and cost of repair.

7) Compatibility - the ease with which the device can be adopted into the existing system.

(a) Perhaps it would be more meaningful to consider only the relative cost of acquisition versus operation. This is the cost of capital to the firms compared to the real costs of variable inputs over the life of the device. 


\subsection{CONCLUSION}

This conceptual model is based on a cross-sectional perspective of the commercialization process as opposed to the more traditional sequential view of technological development. These two alternatives are complementary approaches to the issues of commercialization. While the sequential view leads to an easy intuitive description of the process, the cross-sectional view provides a comprehensive framework for the identification and classification of issues. The cross-sectional approach endeavors to describe why the process takes $\mathrm{place}$ and what constrains and motivates the development of markets for new technologies. 



\section{ANALYSIS OF CRITICAL ISSUES}

In Section 2, we developed a conceptual model of the comercialization process from a cross-sectional perspective. This approach goes further than sequential views of the process to reveal the underlying motivation and mechanisms in the evolution of a technology. It also shows the interrel ationships between the general topical areas. We shall use this model to organize our discussion of the specific issue areas related to the commercialization of fusion power. Table 3.1 shows the subtopics for each of the general areas.

\section{TABLE 3.1. Taxonomy of Cormercial ization I ssues}

Market Demand

- Role of Fusion Power

- Public Perception

Capacity to Produce

- Technological Transfer

- R\&D Management Strategies
Technological Attributes

- Appropriateness of the Technology

- Extra-Market Factors

- Transactions and Start-up Costs

Institutional Environment

- Industrial Characteristics

- Questions of Property Rights

- Regul atory Uncertainty

The purpose of this exercise is to identify areas that warrant significant analysis and forethought. Such an analysis will provide inputs to the planning process, which are necessary for the viability of the program as well as its credibility. The long lead times involved in the fusion program magnify the costs of an error today and increase the uncertainty surrounding the investment. Thus, research rel ated to comercialization should address the areas that can do the most to reduce such uncertainty.

\subsection{NATIONAL NEED AND THE ROLE OF FUSION}

Whether the impetus for a new technology is "technology push" or "demand pull," the existence of an adequate market for the particular attributes being 
considered is essential for successful commercialization. The proper niche for a technology must be found while it still is in the formative stages. This is a cornerstone of any commercialization program. In defining the nature of the demand for fusion power, the subject can be conveniently divided into two areas: the economic role of fusion power and the public's perception of the technology. The issues rel ated to the role of fusion in the economy are discussed in this section while those pertaining to public perception are considered separately in the following section.

To understand the demand for fusion, it is helpful to look at some underlying conditions. First, the demand for any energy source is a derived demand; that is, energy is valuable because it is used in conjunction with some other input to produce a good or service that is demanded by society. Secondly, the principal sector that will likely utilize fusion technology occupies a unique legal and institutional setting. Problems associated with the incentives of the electric utility industry are discussed in Sections 3.9 and 4.3. Third, the full social costs of alternative approaches must be recognized. As Holdren (1978) aptly put it:

"The central energy problem in the long-term is to choose the combination of sources and uses that maximize aggregate well being." (p. 168).

Because the technology is being developed by the public sector and will likely be used by an industry that is subject to intense public scrutiny, the environmental consequences of fusion power will be closely examined.

A number of subtopics emerge as we seek to identify the role of fusion. First, as nearly as possible, it is necessary to forecast the energy market at the time fusion reactors can be commercialized. The nature of the end use of electricity and other energy forms--residential, comercial, or industrial-and whether requirements will exist for space heating, industrial power, or process heat will be of particular concern. Of course, the allocations seen in the market place are simultaneously determined by demand and supply considerations. It is the relative costs of goods and services that determine consumer choices. Thus, it will also be important to examine the position of 
potential fusion substitutes to determine fusion's role. It has been suggested that as energy becomes more dear, the U.S. will move to more usespecific energy sources, that is a mix of sources each tailored to a particul ar need (Holdren 1977, p. 170).

It would appear likely that the evolution of the fission industry will have a significant impact on the market for fusion power. If the difficulties of the nuclear industry are alleviated and it experiences a very rapid expansion, then the need for a fissile-fuel-breeding hybrid reactor becomes very important. On the other hand, if the fission industry continues to decline, then the need for an alternative energy supply could force the introduction of fusion. On another level, the experience of the fission industry with the regulatory processes for a new technology may discourage the introduction of another complex technology like fusion.

Some individuals may question the value of another study on the demand for fusion or similar technologies in the early 21st century, but the problem is so central that it should continualiy be reconsidered. Such a study should provide planning information on the timing of the introduction of fusion and its potential market share. Also, there is the continual problem of justifying the program to Congress and the Administration. For the fusion program to have credibility, it must be based upon defensible planning documents. Thus, the nature of the demand for energy beyond the year 2000 and the role fusion can play are also essential to the program.

\subsection{PLBLIC PERCEPTION OF FUSION POWER}

The second set of demand-related issues involves the public's perception of and reactions to fusion power. Although individual consumers will not directly purchase fusion technology, they may prefer certain technologies employed to generate electricity or other retail-level energy sources. As mentioned in the previous section, the utility industry is exposed to public comments expressing individuals' preferences on the characteristics of production technologies. As we now clearly realize, events of the past decade have demonstrated that public perception of a technology is critical to its success. 
A number of public perception issues arise. For example, is there a perceived need sufficient to justify a technology's cost of development and its implementation in place of another technology? The public will also be concerned with the relative availability of other technologies. The perceived distribution of benefits from the development and utilization of fusion reactors is also important. One of the key factors leading to the demise of government support for the supersonic transport (SST) was the narrow distribution of benefits from the program. If fusion is utilized as a power source for central station electricity generation, then the distribution of benefits should not present a problem for public support. Alternatively, purely industrial uses might be a problem because the public benefits are less direct.

Fusion is so much in the public sector that it is already subject to public scrutiny and will be increasingly scrutinized in the future. Thus, the perceived external as well as private costs of the technology will determine the public's support for the fusion program and its long-run viability. Ultimately, all of the characteristics of fusion must be considered since the benefits and costs are borne by society. This leads to a somewhat broader question about the compatability of the technology with the general trend in society, that is, large-centralized institutions versus small-decentralized ones. It has been argued that "... energy sources should be chosen to fit the sort of society we want not vice versa" (Holdren p. 178). This has one el ement of truth, but we must keep in mind that demand is a function both of consumers' tastes and the relative prices. Thus, efficient new technologies, themselves, influence social institutions.

\subsection{TECHNOLOGY TRANSFER}

One of the most difficult and important problems in the commercialization of fusion power, or any other federally developed technology, is the transfer of the technology to industry and the using sector. Although technology transfer is most often thought of in the context of transfers from developed to less-developed countries, there is another dimension to the problem. In 
this case, the problem is one of the flow of the appropriate technological information from the government and their primary contractors to manufacturers, utilities, and other potential users. Similar difficulties arise in the flow of knowledge from the inventor to the producer, from universities or research labs to manufacturers, and even within a single firm from the scientific 1 aboratory to the production department. As least within the economics literature, technology transfer within an economy is not as well understood or researched as the problems of technological transfer between countries.

Because the mechanism of technological transfer is not well understood, there is a tendency to believe that it is highly idiosyncratic. Due to the relative consistency of objectives and the reduced costs of communication, one expects that exchanges of technological information within a fim are more easily obtained. However, there are several sources of information external to the firm. The relative importance of each source can suggest some factors important to the transfer process. In a review of studies on this topic, it has been shown that other industries are consistently the most common source of innovative scientific and technological knowledge (Pavitt and Walker 1976). While the three studies reviewed focused on the United Kingdom's economy, the results should be somewhat general. The studies suggested that between $33 \%$ and $53 \%$ of the knowledge inputs that led to innovation were obtained from external sources came from other industrial firms.

The second most important source was government-funded 1 aboratories with a range between $18 \%$ and $50 \%$ of the knowledge inputs. Given the difficulties in maintaining a market for information, the relative importance of industrial firms as sources cannot be overlooked, especially in the United Kingdom where the government provides substantial support for research. Personal contracts and personnel movements were common methods of acquiring information from external sources.

These findings suggest that early industrial participation will be vital to the transfer of fusion technology. In general, other industrial firms are important sources of information leading technological change. Thus, industry's widespread participation in a research program will facilitate the 
process as subcontractors and suppliers work with the contractors. The mechanism most often singled out was the transfer of personnel and other direct personal contracts, which, of course, would be encouraged by the direct involvement of industry in the research. This accounts for the transfer of essential knowledge. However, substantial technical support will be required to sustain a large, ongoing fusion industry. The question of how and why industries decide to provide these support capabilities should also be investigated. The answers to this question could be used to motivate industry to provide these capabilities.

A principal element of the transfer could be described as industrialization. That is, an industrial base must develop concurrently with the technology if fusion is to rapidly and smoothly penetrate the market after its commercial feasibility is demonstrated. Industrialization implies not only the "know-how" and capacity to produce a given product but also the supporting specialist firms that can economically supply the primary manufacturer. The more specialized services that are needed by a technology, the greater the technology transfer problems. As the need for such services increases, the likelihood that a single organization cannot produce the technology increases. This will increase the number of organizations that must receive the knowledge. In the case of fusion power, it will likely require the support of a number of specialist firms because of its complexity.

Joint public/private demonstration projects can frequently serve a dual role by reducing technological uncertainties and promoting technological transfer through industrial participation. It is desirable to involve several private-sector participants to promote a competitive vendor industry. Past analyses of demonstration projects have revealed several factors influencing their success (Baer, Johnson, and Merrow 1976); they are reviewed in Section 4. Other questions remain on how to best encourage private-sector participation before the demonstration project, when is the proper time to pursue parallel projects, and when should multiple vendors be utilized? 


\subsection{R\&D MANAGEMENT STRATEGIES}

Commercialization $p l$ anning must be an integral part of the R\&D strategy and management practices of the Office of Fusion Energy (ETM) in the same manner as it is in private firms. In effect, DOE has nationalized the development of new energy technologies, which is a significant escalation of the government's involvement in technology development programs. In the cases of the Department of Defense and NASA, the government was the primary user of the new product and commercialization was a secondary concern. Because DOE is developing and demonstrating future energy supply technologies, it has become a major component of the long-run energy supply industry. However, since the government's involvement is limited to technology production, the transfer of the technology to the private sector has become a problem. That issue was previously discussed in Section 3.3. The corollary problem is how to manage the fusion program to achieve that transfer.

The managerial problem that ETM faces is how to develop viable strategies and plans that balance short-term gains with the long-term goal of successful cormercialization. This problem is made more difficult by both the nature of the economic incentive system facing decision makers and political intervention in the "market". Authors such as Eads (1974) have pointed out the difficulties of achieving efficient resource allocations for research and development in any bureaucratic organization. In addressing such issues as the diversification and funding of competitive approaches, short-run "successes" will be favored over long-term gains even if society views the long-term approach as preferable. The nature of the budgetary process tends to reduce the R\&D management time horizon and encourage short-term successes. The incentive system is also a problem since any decision process is inevitably linked to the residual claims on the returns to the investment. In the public sector, nearly all of the benefits from appropriate decisions are external to the incentive system; decision makers do not have adequate incentives to develop concepts that will eventually result in better long-term technologies rather than develop less-effective short-term options. It may be even more difficult to get the entire budgetary system to use this developrnent 
strategy, encouraging such long-term technologies as fusion, than it is to find the best way to implement fusion technology in the first commercial plant.

One issue in the R\&D strategy for fusion is the role of hybrid fusionfission reactor concepts. If uranium becomes relatively expensive as an LWR fuel source, then hybrid reactors will be of some comercial benef it as well as serving as stepping stones to pure fusion. As a part of the R\&D strategy, the knowledge gained from operating a fusion device would be valuable. Other issues associated with R\&D management strategies are related to the responsibility of the government at these various phases in the technology's maturity: proof of technical feasibility, engineering development, demonstration facilities, and initial comercial plants. These responsibilities need to specifically defined, as well as how industry and their associations can and will be involved in the program. Some energy industry representatives have challenged the government's use of demonstration plants in the syn-fuels program (slick 1976). They have suggested that the traditional concept of a demonstration plant be abandoned and that development progress from pilot plants to a "pioneer" plant, which would be designed for sustained operation. This would be an important consideration for the fusion program because of its capital intensity.

Industrial participation in the fusion development program will be very important both in the transfer of the technology to the private sector and in the perfection of the characteristics of a fusion power reactor. However, Congress expects to see significant near-term industry involvement. How much "involvement" we can reasonably expect in the short-run is questionable. Fusion power is still a long way from commercial introduction, and thus the present value of any private benefits from the use of the technology is expected to be small. It may well be in the best interest of private firms to behave strategically and not offer to fund a project that the government will fund. One should thus be carefully avoid drawing any inferences from current private-sector involvement (or lack thereof). How to best use industrial firms at this time is a significant problem facing DOE. 


\subsection{APPROPRIATENESS OF THE TECHNOLOGY}

Individual characteristics of fusion technology must be appropriate for the needs of the producing and using sectors of the economy. Several previous studies focused on the desirable and undesirable characteristics of fusion from the utilities' perspective (Ashworth 1976, 1977; DeBellis 1977; and Wolkenhower 1977). Our discussion in Section 2 emphasized the role of nonprice considerations in the choice of new technologies. The importance of these considerations has been supported by a recent study of the decision criteria used by industry and utility executives to select power-generating equipment (Laity et al. 1979). Because of the large-scale and difficult physical problems, fusion will not be an exact substitute for current energy technologies.

The characteristics of the technology related to the demand for fusion power include: relative factor inputs, functional performance, system compatibility, and reliability. Characteristics that affect the divisibility of the fusion reactor into subcomponents and the ability to scale-up the fusion reactor will impact the supply side of the market. A user's evaluation of the direct costs of a technology are based upon such relative factor inputs as labor, materials, and R\&D. The purchaser's sensitivity to shifts in their costs is determined in part by the cost of capital to the firm. It would be helpful to understand the sensitivity of the direct costs to changes in the prices of labor, natural resources, and capital equipment, combined with variations in the discount rate (cost of capital to the firm).

An analysis of utility decisions on the purchase of generating technologies suggests that the costs of unreliable systems are a very significant issue to potential users. Uncertainty about the reliability of fission plants has reduced the diffusion rate of the technology in the electric utility industry (Sommers 1978). The functional performance of the technology is obviously an important consideration. This would include the concurrent risks of environmental damage, which are discussed in Section 3.6. Compatability is a related concern, which can be viewed at several different levels. At the broadest level are issues like the degree of centralization society prefers 
and the characteristics of fusion that suggest it will be a 1 arge centralstation technology. What might be called institutional compatability is at the next level. This concerns the ability of current institutions (individual firms, power pools, joint ventures, etc.) to utilize comercial-scale fusion reactors. The grid compatability of fusion would be at the most micro-level. An example of this type of problem would be the operating characteristics of the very early tokamak concepts that made them difficult to connect directly with a firm's electric transmission and distribution system. Because of lower transaction costs, the more a technology satisf ies the performance criteria of existing systems, the faster it will penetrate the market.

Characteristics of the technology also affect the supply side of the market or vendor industry. The greater speed and flexibility with which the industry can offer fusion technology to potential users, the greater will be the comercial success of fusion. Here, flexibility is the key. If fusion reactors can be designed to facilitate component construction, then conceivably vendor entry into the industry would be encouraged. A competitive supply sector including reactor vendors and subcontractors will, in most cases, increase the market penetration of the new technology. Most characteristics of fusion technology will relate directly to issues in the three other elements of commercialization.

\subsection{EXTRA MARKET CONS IDERATIONS}

Considerations beyond the direct private costs, reflected by the market price, of development are equally important to the public in determining the desirability of fusion energy. The problems of environmental damage and safety are referred to in a number of sections of this report because of their interrelationship with the efficiency of market choices, which require the price of the final product to reflect the total social costs. These include the demand for fusion, the institutional and regulat ory requirements considered in Section 3.10, and our own recommendation for further work.

The fundamental issue becomes "To what extent can the hazardous aspects of a technology be easily internalized?" By internalized, we mean capable of being fully reflected in the price of the final product. Where the risk or 
direct impacts must be borne by society at 1 arge, two inefficiencies can occur. First, there is the well-known tendency for over production from that particular technology, in that the market price would be less than the true marginal social costs. At the other extreme, special interest groups that are very sensitive to the external cost can effectively reduce the utilization of the technology below the level that would have been chosen in a perfectly functioning market. If the health hazards of a technology are largely confined to occupational risk, then the costs can and will be internalized. To the extent that such internalized costs become a problem, it is a political not an economic issue. Based upon our current understanding of a fusion reactor, the health impacts should be internalized to a greater extent than those of fission technology.

One of the lessons learned from the fission industry's history is that comercial reactors should not be put into operation until the complete technology is in hand. Problems over the full life cycle of the plant must be resolved for the technology to be credible. The fuel cycle for LWR technology has not been completely resolved nor have all of the waste management problems. These are contributing to the energy industry's lack of commercial success today. Fusion reactors as they are now envisioned will have a relatively high volume of activated products, which will impose a cost for low-level waste management. Holden (1977) suggests that fusion still has an advantage over fission/LMFBR technology because it has some flexibility in the choice of the materials that are exposed to neutrons and the radioactive materials from fusion are shorter lived.

On a broader scale, the rel ative environmental costs of fusion technology seem to compare favorably with those of the LMFBR. It has been estimated the relative radioactive hazard of tritium is one-fourth that of the fuels in a breeder reactor (Haefale et al. 1976). The separation of tritium from water is a significant environmental concern that remains to be overcome. Relative to fission reactors, a fusion plant is less prone to castastrophic accidents-the cost of which are very difficult to appropriately internalize through either a market or regulatory mechanism. A fusion reactor, unlike a fission 
reactor, will not be subject to the problem of criticality. The worst case accident would be a lithium fire (the lithium is the 1 argest source of stored energy). Even in this case, public exposure to radioactive tritium oxides would be approximately one-hundredth the hazard of a hypothetical fission accident (Holdren 1977).

With respect to other extra-market factors such as mining, thermal pollution, or nonproliferation, fusion technologies offer society more advantages than other long-term energy options. Advanced fusion fuel cycles offer even greater promise. Many of the hazardous characteristics of the technology are capable of being internalized by the market, given the proper institutions. This leads to another issue on regulatory requirements for fusion, discussed in Section 3.7 .

\subsection{TRANSACTION AND START UP COSTS}

The frequency and divisibility of transactions are important determinants of a market mechanism's efficiency. The nature of the transaction is a function of characteristics of the technology. The issues discussed are 1 argely from the perspective of the user and are closely associated with the scale of operation. In this area, the start-up costs are also of concern, particularly with respect to the training requirements for operators.

In the past, the characteristic of fusion technology most widely criticized by the electric utility industry has been the perceived scale of the reactor (Wolkenhauer 1977). Although current reactor designs are for smaller and smaller units, earlier commercial plants are not likely to be small-scale. The reactor scale can create difficulties in many areas of the market. The potential market is limited to the number of utilities able to absorb 1 arge generating facilities. Acceptable sites are reduced and potential diseconomies of scale could be experienced in financing the plants. Even after the fusion reactor is built, the utility bears additional risks from forced outages. At 1 arge scales, the number of plants ordered by a given utility will reduce costs by making transactions uniform. 
Another set of characteristics that will impact the entry costs are those related to the learning curve potential. Learning can be experienced at levels that are both internal and external to the firm utilizing fusion technology. Due to the complexity and uniqueness of a fusion reactor, the "learning potential" is likely to be great. Because the learning that occurs at the industry level increases the relative costs of the first plants, vendors may avoid early entry into the industry. Learning-by-doing at the industry level occurs when costs of fusion plants for vendors are reduced because of overall experience in building and operating fusion reactors. This creates a $\mathrm{classic}$ positive externality, that is the 1 arger the industry, ceterus paribus, the lower the cost of building for any one firm. This would imply that the first few plants should be subsidized to encourage industry participation.

If the benefits from learning accrue largely to the vendor then the first firm into market will achieve an "economy of scale" that will deter further entry and reduce competition in the vendor industry. If operators of fusion reactors are faced with significant "learning costs," then the effective first costs of the plant are increased. Thus, entry by 1 arge utilities will be encouraged more than entry by smaller utilities since the large firms could spread the learning costs over more and 1 arger units. This will again reduce the potential market. In a related issue for operators, the manpower training costs will impact the fusion plant start-up costs in the same manner. If the reactor's operating personnel require extensive and unique training, then this will become an additional transaction cost for the utility adopting the new technology. These costs probably will not be substantial enough to block the utilization of fusion, if it is otherwise acceptable, but they could slow the rate of market penetration.

\subsection{INDUSTRIAL CHARACTERISTICS - UTILITIES AND VENDORS}

Characteristics of the electric utility industry and suppliers are constantly changing in response to new technologies and institutions. The utility industry is undergoing significant change and will undoubtedly look 
much different by the time fusion is introduced. To be successfully commercialized, a technology need not be a perfect substitute for the one it is displacing because the industry will, to a certain extent, change to accommodate a new technology. Likewise, technology will impact the structure of and ease of entry into the vendor industry and the structure of the vendor industry will influence the incentive to promote new technologies. A large body of economic literature has developed around the impact of market structure on technogical change (Kamien and Schwartz 1975). The areas we have considered include the size and structure of the utility industry, the impact of rate-ofreturn regulation, and entry into the vendor industry.

Some studies have begun to consider the size and structure of the U.S. utilities at the time when fusion will become comercially available (Deonigi and Fral ey 1978, DeBell is 1977). Given the utilities' concern regarding the scale of fusion reactors, this is an important factor. However, such a study needs to be broadly based and address not only firm size but also regional power demands, transmission technology, and joint ventures. The role of power pools and joint ventures in the construction and operation of gener ating facilities has become especially important in utility system planning. As many as one-half of the LWRs have been purchased through some type of formal joint venture. (Somers 1978). In the future, financial considerations may encourage further use of joint ventures if a large portion of the costs of technological uncertainty are borne by the investors. For example, if the costs of a plant shutdown due to an accident were to be removed from a firm's rate base, the financial risk to the firm would be substantially increased.

The electric utility industry functions in a regulatory environment. The impact of rate-of-return regulation on the industry's technology choices has been extensively discussed in the economics literature. Theoretical arguments suggest that utilities will favor technologies that are very capital intensive. However, empirical support for this hypothesis has been inconclusive. For the commercialization of future technologies, it would perhaps be more instructive to consider the influence of marginal-cost pricing and time-of-day metering 
both on demand and on appropriate generating technologies. Other aspects of regulation that could be potentially significant include the sensitivity of regulation to special interest groups, the impact of reliability on regulatory "costs," and changes in financial regulation.

The nature of the vendor industry will influence the commercial success of fusion technology. Although it is a matter of debate whether a monopolistic or a competitive industry will adopt technological change faster, a competitive market will eventually achieve the broadest market penetration. The desirability of small fusion systems have been considered in several previous sections, and the issue is again important in determining the structure of the vendor industry. The reduced capital requirements for small systems will likely make entry into the market easier. We cannot, a priori, determine the impact of such other factors as the role of architecture and engineering firms as prime contractors or the use of component designs that require highly specialized manufacturing facilities. The electrical equipment industry has historically been highly concentrated, subject to antitrust review. At the same time, the scale of the major firms enabled them to finance and offer "turnkey" contracts on the first generation commercial fission reactors. The questions that remain on the total impact of market structure suggest that it warrants further examination in the context of fusion technology.

\subsection{QUESTIONS OF PROPERTY RIGHTS}

There are a wide variety of institutional arrangements that affect ownership and the willingness to exploit a technology for private gain. For a new technology, questions of property rights may determine the effectiveness of the market mechanism: A critical factor in determining a firm's potential return from an investment in a new technology is the ability to maintain the rights to this new technology. The rights to tangible or intellectual property are defined and regulated by the government. The government's legal and regulatory institutions can either increase or decrease the efficiency of private transactions. The scope of topics related to property rights ranges from the involvement of private industry in R\&D planning activities to the legal status of nonutility firms that build and use fusion reactors. While these may appear a diverse lot somewhat removed from the present focus of the 
magnetic fusion program, no other set of issues will be more important to the commercialization of fusion power in the long run.

One of the first activities of the U.S. Government was to establish a patent office to define and protect intellectual property. The role of government in this area is justified on at least two grounds: 1) in the market for information or even the application of knowledge, it is very difficult to maintain effective control of the property; and 2) the development of new technologies stimulate increases in real national income and should be promoted by enforcing exclusive rights to innovations. Under current statutes, contractors are granted rights to patents developed in the course of their DOE sponsored research, but, in most cases, DOE maintains the title to the patents. DOE has the authority to waive part or all of their right to the patent title. "Background patents", patents that a contractor developed prior to its DOE contract but related to the research contract, also present an ownership problem (National Research Council 1978). It is possible for DOE to license these "background" patents to disseminate information. Under these conditions, a contractor's primary interest may we 11 be in the research contract itse if and less in the commercial potential of the research output. The government could thus lose any synergism with the private research interests of the contractor. Laying aside the issue of whether the title policies specified for DOE contractors are justified by equity considerations, contractors' uncertainty about their proprietory position may be sufficient for them to alter the ir behavior. (a)

(a) This has been one of the most controversial areas of government policy, as discussed by James Denny (1978, p.5): "Some have asserted that the license policy was the most effective policy since it provided the maximum use of the patent incentive and induced prospective contractors to bring their background knowledge and commercial experience to bear on Government tasks, thereby tending to reduce the cost of Government research. While others argue that the most competent contractors would refuse to perform $R \& D$ work for the Government, or even worse, if they did perform such work, a title policy would tend to induce contractors to isolate their commercial know-how and competence from their Governmental tasks." 
Given the time frame for magnetic fusion development and the 17-year period of patent rights, this controversy surrounding patent rights may be a minor point. However, the uncertainty must cloud the relationship between DOE and industrial contractors. It is entirely possible that a more immediate patent application could be made for an invention arising from fusion-related research but the benefits from such a patent would be sharply constrained. The absence of such potential profits would suggest that industrial participation could be delayed. Further work needs to be undertaken to gain a fuller understanding of the role of early patents in the development of a large and complex technology.

Open government rules and conflict-of-interest regulations can inhibit the free flow of information between interested industrial firms and federal R\&D managers, which raises another area of concern. This topic has been explored briefly in general terms by the National Research Council (1978). Within the U.S., there has been a legitimate drive toward opening the decisionmaking process to the public. This drive has spawned the Freedom of Information Act, Government in the Sunshine Act, and the Federal Advisory Committee Act. The rules defining conflict-of-interest by DOE contractors are also of concern. Uncertainty regarding the protection of information disclosed to DOE and problems regarding conflict-of-interest in follow-on contracts may limit the willingness of the most-competent industrial contractors to become involved in R\&D planning.

Industrial participation is looked to as a major milestone in the commercialization process. Industrial participation is strongly correlated with the successful demonstration of a new technology, and it is held out by Congress as proof of the commercial potential of a new technology. For numerous reasons, it is unlikely that private industry will invest significant amounts in fusion research at this time. Thus, the most likely form of industry participation at the present time would be in the planning of activities. If federal regulations inhibit this industrial participation, then the 
magnetic fusion program could be impacted far beyond the loss of the private sector's full participation in the planning process, due to Congress's reaction.

Antitrust concerns arise in three different areas: the competitiveness of the vendor industry, restrictions placed on the users of fusion reactors, and private-sector involvement in joint R\&D planning activities. The latter concern was discussed above in the context of other legislation. Federal antitrust regulations that restrict the nature of discussions carried out by competitors or potential competitors could also inhibit industrial participation. These problems were also elaborated on in the National Research Council's (1978) report.

The competitiveness of the vendor industry will influence both the market for fusion power's rate of development and the investment costs that users will face. For the private sector to make the investments that are necessary to commercialize a new technology, there must be some possibility that they will earn a competitive return. A firm's ability to maintain effective rights to the returns from such an investment is one element determining a firm's return on such an investment. Patent protection is one route to maintain these rights. A technology may be so complex that the first firms to enter the market can build up an insurmountable lead in producing and marketing the technology. The policies and programs for commercializing a technology must provide adequate private incentives for producers but prevent a firm from establishing an effective monopoly.

The restrictions placed on potential producers and users of fusion reactors form the third area of antitrust considerations. New technologies offering different economic characteristics place pressure on the existing industry to restructure in order to obtain the maximum efficiency from the new technology. Firms or individuals with vested interests in the present structure will lose and thus tend to resist change. Antitrust law could be one avenue for that resistance. In the past, the NRC established an antitrust division at the request of small utilities. The extent to which such regulation restricted the diffusion of nuclear power is uncertain, but the potential impact of 
similar regulation on other large-scale technologies, such as fusion, could be significant and should be considered.

The property rights issues previously considered will potentially impact fusion commercialization through the supply sector. That is by insuring the incentive for vendors to enter the fusion market. Other property right-type issues will have an impact through the demand side of the market. Several uses of magnetic fusion reactors beyond central-station electricity generation may be feasible. If development of a hybrid reactor is sought, then fuel production will be the principal output of the facility. However, regulations could limit the effective demand for a hybrid technology because present utility regulation tends to discourage private utilities from owning and producing their own fuels. At the same time, a nonutility firm, interested in hybrid reactors for their breeder characteristics, could be forced under utility regulations if the plant produced electricity or process heat that was sold to the public. Cogeneration issues affecting several smaller-scale technologies were addressed in the National Energy Policy Act. It would be helpful to have a comprehensive review of cogeneration issues and the rights of firms engaged in electricity production to see that the laws are compatiable with new technologies for the efficient production and use of energy resources.

\subsection{REGULATORY UNCERTAINTY}

Today the uncertain regulatory environment is casting a cloud over the utilization of any new technology. Because of the complexity of fusion reactors, regulation could be particularly sensitive. Thus, early resolution of environmental and safety regulation problems will be a key factor in the commercial success of magnetic fusion. There are three areas of concern because of uncertain regulatory requirements: an unstable investment climate, possible cost escalations, and liability rules. The first two considerations are, of course, very closely related. Corporate managers are very reluctant to commit capital funds to an investment when they cannot determine when the investment will begin generating a positive cash flow and how much of the investment will be allowed in the rate base. It will be substantially more 
expensive to meet changing regulatory standards than to initially plan on the stricter standards. It can change an otherwise economic plant into an inefficient investment. The third area of concern relates to requirements for special liability rules. The Price-Anderson Act was helpful to the commercialization of fission reactors, so something similar may be advantagous for fusion commercialization. One outgrowth of the Three Mile Island incident, which may also affect fusion power and other large-scale energy technologies, will be the resolution of who is financially responsible for plants that are shut down for extended periods of time.

Several observations can be made from the recent experience of the LWR industry. The lack of experience by the regulatory body has resulted in subjectively determined standards that are constantly reviewed and amended. These changes in environmental and licensing rules have created bottlenecks in the supply process that have shifted the relative prices in favor of other fuel types. The factors that have created this situation include: public concern for the independence (or lack thereof) of the regulatory body; the need for R\&D capabilities supporting the regulators; and, finally, the safety of the complete technology must be established prior to commercialization. Given the complexity of fusion reactors, environmental and safety issues must be addressed objectively early in the development of the technology.

Three hypotheses emerge concerning the impact of regulation on new largescale technologies. Regulatory uncertainty can prematurely impose product standardization. It is natural in the evolution of a new technology for its production and characteristics to converge to some "standard" process and product. However, if this "standard" is imposed arbitrarily, then product quality may we 11 suffer and the least-cost method of production may not be found. The catalytic converter for automobile emissions is an example of this. This type of prescriptive regulation does little to promote efficient technological change. The second hypothesis is that regulatory cost will tend to increase the minimum efficient size of a reactor. The expense of compliance with regulatory standards is fixed relative to the reactor's capacity; to offset this cost on a per unit basis, the size of the reactor can be increased. The 
impact of increasing the minimum-efficient plant size will decrease the potential market for fusion reactors. The final hypothes is is that regulation can become a entry barrier for other potential vendors because of increased fixed costs and limited product differentiation. The impact on the market would be fewer units sold, less price competition, and possibly lower quality competition.

In today's environment, the problems of environmental and safety regulation are quite complex and very important to the comercialization potential of fusion power. We have discussed this area further in Section 5, Topics for Future Study. 


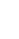


4. COMMERC IAL IZATION OF LARGE-SCALE TECHNOLOGIES: RECOMMENDAT IONS FROM THE LITERATURE

Paul Sormers (a)

Molly Selvin(a)

In this section, we examine the economic issues associated with the commercialization of 1 arge-scale technologies through a review of the relevant economic literature. The relevant literature includes studies of innovation, diffusion, technological change, technology transfer, and policy strategies. This literature review focuses on the issues involved in commercializing the entire generic class of technologies that can be classified as large-scale technologies. Most of the conclusions that we reach apply to the commercialization of all technologies, not just to 1 arge-scale energy technologies or to large-scale electric power technologies.

The insights and policy suggestions offered in the relevant literature are somewhat 1 imited. Research needs are as apparent as research findings. Therefore, both the findings and the gaps in the existing literature are summarized below with emphas is on the problems of commercializing large-scale technologies.

\subsection{POLICY STUDIES}

The policy issues literature identifies effective policy strategies that are designed to encourage or facilitate commercialization. The publications relevant to fusion comercialization fall into four main categories: 1) retrospective case studies of the commercialization of one particular technology, 2) studies that evaluate and compare a number of domestic and foreign commercialization and demonstration projects, 3) prospective studies of the barriers to the commercialization of several energy technologies, and 4) studies that consider macro-level science and technology policies. While both energy and

(a) Battelle's Human Affairs Research Centers, Seattle, Washington. 
nonenergy related technologies are examined in this literature, we attempt to draw general conclusions that are applicable to the comercialization of largescale technologies. Typically, the case study and the comparative approach as have been used to 1) isolate effective policy strategies and highlight policy mistakes in past commercialization and demonstration projects, 2) identify the institutional and political barriers to the future comercialization of energy technologies, and 3) explore the appropriate roles for policy makers who attempt to encourage commercialization.

The case study approach was used to study the commercialization of the LWR between 1954 and 1974 (Perry et al. 1977 and Rolph 1977), the history of the U.S. Supersonic Transport Program between 1961 and 1971 (Bugos 1976), and the history of the U.S. government's synthetic rubber program between 1941 and 1955 (Samuelson 1976). These comercialization programs were plagued by a number of common problems including regulatory delays, uncertain degrees of government comitment, insensitivity to political and institutional issues, inadequate technological knowledge, and poor program leadership.

The authors of these case studies purport to have learned several "lessons" for present energy policies. First, government commitment to commercialization should not be half-hearted; funding should be well defined and regularly forthcoming. Second, a strong technical agency with a wellestablished mandate should direct the project. Third, a thorough investigation of environmental, social, and national and international political impacts of a particular technology should be an integral part of the R\&D program. Fourth, policy makers should realize that an industry is really a combination of separate sectors. Thus, overall goals should be set and programs in separate sectors should be coordinated. Fifth, the relative mix of government and private efforts in an initially government-supported industry must evolve over time with changing economic conditions. Sixth, policy makers must realize that their decisions have impacts over a much longer time period than the planning horizons within which they are made.

The second group of policy studies is more diverse than the case studies group. This collection of reports and articles includes evaluations of demonstration programs; comparative assessments of comercialization strategies in 
the U.S., Canada, and Britain; and analyses of various federal incentives designed to facilitate the development and commercialization of energy technologies. The authors of each of these studies have also drawn "lessons" for future energy policy makers.

McFetridge (1977) and the MIT Energy Laboratory Policy Study Group (1976) have taken a theoretical approach to governmental R\&D spending and commercialization programs. Both reports question the wisdom of government intervention in these processes. McFetridge offers a narrative microeconomic analys is of $R \& D$ spending by the $C$ anadian government and concludes that most government functions in this area are more efficiently performed by private institutions.

The MIT report also examines government's proper role in comercialization and concludes that comercialization programs represent a departure from normal government functions. In the traditional model, the government supports $R \& D$ by funding the research and/or using it, but the government leaves most decisions about the pace of R\&D and the use of R\&D products to the profit-seeking calculus of the private sector. Short-run energy shortfalls and national security worries have forced a departure from the traditional model, but policy makers must carefully evaluate the current situation before subsidizing commercialization programs. The report describes two distinct conceptual models of the energy system. The Gaps Model concentrates on physical energy flows and on the potential of new energy sources to fill projected gaps between sources and uses. The Price Model notes that without government controls supply always equals demand at some price and holds that the important question is: what price are we as a nation willing to pay to limit energy imports or to avoid environmental damage? The MIT group prefers the Price Model and assumes its relevance throughout their work.

The report distinguishes four phases of comercialization: invention, development, introduction, and diffusion. It recommends that ERDA examine this complete process of commercialization by looking for reasons why private markets do not always produce desired results and considering whether government interventions can produce better results. The report suggests that government intervention may be indicated if the analyses indicate that the private sector's investments in R\&D are too low. 
The scale of novel technological programs such as nuclear power development is such that no private sector consortiun can assemble the resources for a long enough time period to make a profit from their investment. These technological programs involve issues of public goods, the government in a regulatory mode during and after commercialization, and resources that belong to the government (property, ideas).

An intriguing view of the commercialization process approaches R\&D at the invention-innovation stages as options (in the stock market sense) that may be used to produce a profitable product at a later stage. They do not produce profits directly; they just open doors or keep them open. However, by the introduction and diffusion stages, further investments are expected to produce profits in a fairly direct sense. A product goes into production and is expected to be sold, or a new production process is put into operation. Profitability is the sine qua non of such investments.

This conceptualization helps define the purpose and expected output of R\&D at various phases of commercialization, even though the phases are often somewhat fuzzy and overlap. Consequently, an option-type R\&D investment might be undertaken at any phase, or bits and pieces of such an invention might end up in profit-producing operation much quicker than anyone expected. The optimal combination, timing, and institutional location for option and direct profit-producing investments in a comercialization process is a subject area that the MIT report has hardly touched.

Cone et al. (1978) examined past and present federal incentives to the production of various energy sources in an effort to assist DOE in the recommendation of federal incentives for the development of solar energy. The report identifies several types of incentives.and quantifies federal expenditure for incentives to support nuclear power, hydroelectric power, coal, oil, natural gas, and electricity. By noting the extensive precedent that exists for federal support of energy development, the Cone report stongly endorses the use of federal resources for the commercialization of solar energy technology. 
Apart from these three reports, the rest of the literature in this group does not question the wisdom of whether the government should attempt to encourage commercialization; rather, the remaining reports and articles debate how government should encourage comercialization.

Baer, Johnson, and Merrow (1977) studied 24 federally funded demonstration projects to determine which commercialization strategies encouraged the fastest rate of diffusion. They found several characteristics that could accelerate the commercialization of a new technology including cost-and-risk sharing with nonfederal participants, a well-tested technology, initiative for the project at the local level, a strong industrial system for commercialization, participation in the demonstration by those who will take responsibility for further diffusion, and the absence of tight time constraints. The study also concludes that demonstration projects should have a narrow scope for effective use. They are most successful when the diffusion would otherwise be hampered by potential adopters' lack of knowledge about the use of the technology under commercial operating conditions.

The Charpie Task Force Report (1978) contains a number of recomendations for ERDA commercialization programs. Energy commercialization planning should be integrated into the agency's organizational framework. Very careful attention should be paid to private sector RD\&D initiatives in order to maximize private sector effort and to involve the private sector wherever possible in ERDA programs. Demonstration projects should play a major role in ERDA commercialization efforts if the demonstrations involve fully developed technologies with a clear potential for economic viability of the end of the demonstration.

DeYoung and Tilton (1975) studied the introduction of 1 arge-scale generating units in the U.S., Canadian, and British electric utility industries and found the reasons for the slow rate of adoption of generating technology differed in each country. However, in both the U.S. and Britain, the major factors impeding adoption are institutional and presumably could be eliminated by appropriate government action. In the U.S., the major factor determining the introduction of 1 arge generating units is firm size. Public policy can facilitate adoption by encouraging interconnection and joint ownership agreements, 
or by encouraging small firms to stop generating their own power and buy it wholesale from neighboring utilities. In Britain, the government could facilitate adoption by encouraging the decentralization of the utility industry into regional units.

The potential barriers to the commercialization of various energy technologies are the third group of policy studies examined. Bezdek et al. (1971) and Hirschberg and Schoen (1974) analyzed the policy options for accelerating the commercialization of sol ar heating and cooling systems. In these reports, how various incentives might work is explored rather than how they have worked in practice. Bezdek et al. examined the relative effectiveness of such incentives as low-cost or low-interest loans, guaranteed loans, government procurement, income tax credits, demonstration programs, and a tax on fuel. Bezdek et al. and Hirschberg and Schoen conclude that low-interest loans, guaranteed loans, government procurement, and income tax credits would all act as significant incentives to the commercialization of solar technology. Demonstration programs and fuel tax assessments, however, would have little or no effect on diffusion. This report is consistent with the Baer et al. finding that demonstration programs, by themselves, have little significant impact on commercialization. Hirschberg and Schoen discuss the institutional and organizational barriers to the diffusion of solar heating technology in the U.S. housing market and suggest a number of strategies for comercialization and diffusion. They note that, within the U.S. housing industry, technically feasible and economically competitive innovations often fail to achieve rapid commercial acceptance. This failure, in their view, has been mainly from not realizing that a combination of technical, economic, and institutional activities must be persued before diffusion will occur.

Eulberg (1979) also examined the policy incentives for comercialization and concluded, with Bezdek, that low-interest loans and income tax incentives represent sound options. Moreover, he suggests that regulatory changes, outright subsidies, and price support programs might encourage the commercialization of 1 arge-scale energy technologies.

Morris et a1. (1978) and Schuller et al. (1976) analyzed the barriers to the commercialization of heliostats and geothermal power in California. 
Morr is et al. outlined six possible commercialization strategies for heliostats and evaluated each using the following criteria: economic efficiency, governmental expenditure, fairness, legal authority, organizational feasibility, political feasibility, and risk. In the report, he concludes that no strategy is best in terms of all seven criteria but he recommends either the federal purchase of heliostats for lease to a utility or federal subsidy of heliostat purchase and operation by utilities. These strategies could create sufficient economic incentives for both manufacturers and users. Schuller et al. identified and analyzed the nontechnical problems hampering the production of electricity from geothermal resources and evaluated possible solutions to these problems. Those nontechnical problems include: leasing, exploration, agreements on utilization, power plant construction, transmission, financing, environmental reporting, the role of the California Energy Cormission, proposed air pollution regulations, and the political economies of individual counties. The analysis draws four major conclusions. First, streamlining an existing operating procedure or regulatory system is preferred over instituting a new one because the participants need less time to learn how to operate within an existing structure. Second, notwithstanding the above, the changes that must be instituted in regulations or operations should reduce the number of times that one participant has to deal with other regulations or operations and increase the attractiveness of geothermal power over other investment opportunities. Third, geothermal developers have to recognize that geothermal resources are different from other energy sources in two ways: more uncertainty surrounds both the discovery and measurement of the resource and its power generation technology, and the efficient plant size is much smaller. Fourth, any analysis of proposals for change should attempt to assess two $f$ actors: the time, money, and trouble required to institute them and the differences they will make, once adopted, in the time, money, and trouble involved in the geothermal development process.

Macro-level science and technology policy studies are concerned with creating the proper economic and institutional climate to encourage commercialization of new technologies. Nelson (1979) calls for a closer integration 
of science and economic policies. The separation of science and economic advisers in the Executive Branch and the separation of research and policy functions in many agencies result in a lack of coordination between these activities. All too frequently, the R\&D and economic policies and programs pursue conflicting ends. Nelson cites energy and housing as examples. Hollomon (1979) indicates that such an integration of science and technology policies exists in Japan without direct government support of R\&D. Japan's government uses economic policies to create a favorable climate for technologically progressive firms. West Germany emphasizes a favorable climate for new technology but also directly supports R\&D through grants, cost-sharing arrangements, and loans. The British have a public, nongovernmental corporation that supports development of innovations. Some of these ideas may be transferable to the U.S. However, in summarizing the MIT Center for Policy Alternatives study, Hollomon noted that cause-effect relationships are very complex in the technology policy arena, and called for very careful consideration of probable industry responses to proposed policies. Finally, the Carmittee on Private Sector Participation in Government Energy RD\&D Planning noted a complex web of legal constraints on private sector participation but called for a formal advisiory panel of academic, industrial, and nonprofit sector representatives to advise the energy agencies on private sector responses to government initiatives in energy RD\&D.

All these types of policy studies point to one general conclusion: the relationships between policy and outcome are very complex, multiple, and interactive. Case studies, program and strategy evaluations, and science and technology policy studies all indicate a limited understanding of the links between policy initatives, private sector responses, and the achievement of policy goals. Some progress has been made in delineating our ignorance of these linkages, but additional research is clearly needed.

\subsection{MANAGERIAL STUDIES}

A number of the reports and publications reviewed for this project have looked not so much at the requirements for commercialization but rather at the 
conditions necessary for innovation within individual firms. A number of authors posit that the organization of firms, managerial styles, and the mix of researchers, entrepreneurs, and other staff members directly affect the rate of innovation within that firm. Perhaps the correct mix of structure, personnel, and management may also determine the rate of commercialization of government-sponsored R\&D technologies.

Paoli1lo and Brown (1978) found that the characteristics of firm size (number of R\&D employees) and structure (number of formal supervisory levels) were negatively related to R\&D subsystem innovation. That is, smaller R\&D units were associated with greater perceived innovativeness. Moreover, this study found that the average size of research teams and the degree of autonomy, creativity, training, and rewards that existed in the organization were positively related to innovation.

Horwitch and Prahalad (1976) have postulated a more complex framework for R\&D innovation. They have found that technological innovation occurs in three distinct modes: Mode I includes technological innovation in small, high technology firms; Mode II includes large, divisionalized corporations; and Mode III encompasses innovation in multiorganizational and multisector settings. Innovation in each type of firm is vulnerable to different dangers. Mode I firms are often $p l$ agued by 1 imited financial resources. Mode II firms are inherently complex organizations that fall prey to internal policy contradictions in pursuing technological innovation. In the Mode III setting, innovation is vulnerable to change because of the highly politicized arena in which it occurs. Large-scale energy comercialization programs would most likely occur in Mode III settings; consequently, policy makers and business leaders must mobilize diverse support and expertise for these programs to be successful. Moreover, since the Mode III-type enterprise is highly vulnerable to public opinion, the outcome of commercialization programs can never be totally assured even using modern managerial techniques. Managers must acknowledge that they are involved in a process where no single group has total control over the enterprise. 
Frohman (1978) and Roberts (1978) contend that research innovation depends on the presence of a number of individuals with quite different skills within the same organization. Project managers, researchers, entrepreneurs, and "gatekeepers" (individuals who gather and channel research information throughout the organization) are all necessary for successful R\&D. Sands and Warwick (1977) and O'Leary (1978) concentrated on the marketing of research innovations, and contend that a "revolutionary new product does not sell itself." The principal causes of marketing failure include inadequate market analysis, product problems or defects, lack of effective marketing efforts, higher than anticipated costs, competitive strength or reaction from other firms, poor timing of introduction, and technical or production problems. They conclude that manuf acturers engaged in technological R\&D will be bet ter able to cope with the inherent risk and cost of developing new products if they adopt formal, systematic approaches to both introducing new products and eliminating weak ones.

McEachron et a 1. (1978) have looked not only at the necessary mix of skills within an organization but also at the interaction between federal R\&D agencies, federal contract research centers, nonsponsor federal agencies, and manuf acturing firms. This report was designed both to describe current policies and practices regarding the management of federally funded R\&D projects that are intended for nonfederal application and to develop a set of empirically grounded recomendations for policies and practices that would improve the commercialization of federally funded R\&D projects. The report recommends using 1) market planning and analysis, and 2) market intelligence and communications techniques. The first recommendation emphasizes the importance of orienting federal R\&D agencies to the marketplace and designing projects to meet producer and user requirements rather than promoting a technology per se. The second stresses the importance of communication and cooperation among the various parties--federal R\&D funding agency, R\&D performer, potential producers, potential users, and other governmental and nongovernmental bodies-whose actions affect the transition of R\&D to the marketplace. 
McEachron et al., of SRI, selected 46 projects in various programs of 11 federal agencies for study. They randomly selected these projects looking for both commercialization successes and failures. From this sample, they hypothesized a number of management guidelines that they believe are critical to the successful commercialization of federally funded R\&D projects. These guidelines affect project planning, project implementation and administration, and project review and evaluation. They then sought to determine how often federal R\&D management actions in the sample were consistent with the posited guidelines by analyzing the relative frequency with which the management actions in their sample of 46 projects were consistent with the guidelines. This analysis found a high correlation between commercialization success and implementation of the management guidelines. In over $75 \%$ of the projects--the major ity of which were drawn from the successful category--managers "usually followed" the guidelines. (a)

\subsection{ECONOMICS STUDIES}

The following categories of economic literature must be considered to reach a comprehensive understanding of commercialization: 1) diffusion of innovation studies, 2) technology transfer issues, and 3) the role of market structure.

(a) This study is not particularly innovative; its findings are generally a restatement of a great deal of previous work on the subject of R\&D management. Moreover, SRI's (McEachron et al. 1978) methodology is, as the report indicates, severely flawed. First, projects were selected with the objective of finding an equal number of successes and failures rather than obtaining a representative sample of the universe of federal R\&D projects intended for commercialization. Second, the report relied on retrospective interviews to elicit management guidelines. Respondents often give faulty information about the past and, moreover, may be likely to exaggerate the importance of management decisions or skills in the commercialization process rather than economic or technological factors. Finally, the authors developed their list of management guidelines based on an examination of the 46 projects. Subsequently, they went back and intervi ewed managers and officials associated with those same projects with regard to the relationship between those guidelines and the commercial success of the individual projects. This methodology does not prove these management techniques were instrumental in the commercial success of various projects; rather, it proves that managers and officials associated with the projects perceived that those techniques were instrumental. 
Diffusion of Innovations

The diffusion-of-innovations literature seeks to explain the patterns by which innovations spread from firm to firm in an industry. Among the variables that the economic literature seeks to explain are the rate of diffusion, the number of potential adopters, and the proportion of industry capacity accounted for by the new technology in the long run. Related work in sociology and anthropology has concentrated on the communication mechanisms that disseminate information about an innovation to potential adopters. Sources and patterns of persuasive communication are the focus of this branch of the diffusion-of-innovations literature. Other disciplines, including political science, are responsible for additional contributions to the literature.

Between the economic and sociological approaches, there is an important complementarity to explaining the pattern of diffusion of innovations. The incentives for adoption are discussed by economists while the mechanisms are the focus of sociologists. This complementarity was pointed out very early in the history of this literature, but it has never been explored in a serious, interdisciplinary study. Such a study would yield many useful insights about possible market intervention strategies.

Much of the discussion about the rate of diffusion is motivated by an assumption that the rate is "too slow." The literature demonstrates that the time required for an innovation to approach the asymptotic ceiling level varies greatly from one innovation to another. Mansfield's (1968) study of process innovations in the railroad, brewing, bituminous coal, and steel industries found that 10 to 20 years are required for an innovation to be adopted by all major firms in the market. Mansfield also reported rather 1 arge variances across innovations in the time required for innovations to be adopted by all major firms. From the limited sample of studies, a decade appears to be about the minimum time required for a major process innovation to diffuse widely, whereas a new component of a close substitute for something al ready used can be adopted much more quickly.

A decade or more for the diffusion of major process innovations, with a wide variance across a class of innovations, would undoubtedly be regarded as 
inordinately slow by government commercialization program managers, However, appropriate policy interventions to accelerate diffusion processes are not well understood. Warner (1974) is skeptical about the efficacy of policy interventions based on the current state of knowledge. Schoen et al. (1975) also note that reports of successful and unsuccessful government interventions in diffusion processes have not been reported in the 1 iterature. Many observers of the nuclear industry have pointed out that government policy changes may actually have slowed the diffusion of nuclear power generation. Additional research in this area is clearly needed. Integration of the insights of sociological and economic research frameworks is one possible model for research on intervention strategies.

The S-shaped cumulative adoption curve phenomenon is the central finding of this body of literature. However, several researchers have noted that this pattern of diffusion is by no means universal or inevitable. Several of the pieces contained in Nasbeth and Ray's (1974) volume question the universality of this pattern of diffusion and suggest that linear or asymetric adoption curves are possible. Asymetric curves may result if a diffusion process starts very slowly or if some firms are exceptionally slow to adopt the innovation. Hamblin et al. (1973) note that if the incentive to adopt varies during the diffusion process then the rationale for the $S$-shaped curve is destroyed. Distinct "diffusion epochs" with exponential within-epoch cumu1 ative adoption patterns may be observed in such cases. The pattern of diffusion across all epochs in this model resembles a scalloped, upward-sloping curve with an asymptotic upper limit. Sormers (1978) argues that the constant incentive assumption is particularly inappropriate in the case of LWR nuclear $\mathrm{pl}$ ants and suggests a much different alternative model.

Large-scale technologies are especially likely to vary from the $\mathrm{cl}$ assical S-shaped diffusion pattern. Long lead times for planning, obtaining permits and construction--plus a rapidly changing economic, political, and technological environment--result in frequent changes in the profit expected from adopting such an innovation. Under these conditions, the user's uncertainty about the advisability of adoption significantly affects the rate of diffusion. 
The experience of previous adopters has not proven a useful guide for potential adopters. This fundamental difference from innovations that conform to the classical pattern results from rapid changes in conditions external to the technology and the adopting firm rel ative to the speed with which adoption takes place. The nuclear LWR, the civilian SST, and fixed-rail transit systems are all examples of this phenomenon.

Many of the general findings of the diffusion-of-innovations literature apply to large-scale technologies that the government might want to commercialize. The expected profit matters; profits, preferably large ones, are necessary to compensate for risk and to motivate the adoption of a technology. $L$ arge investment costs are a deterrent, but are not an insurmountable hurdle, to 1 arge-scale systems if a high enough profit is expected. It is also beneficial for the new technology to be compatible with existing technology and practices. Persuasive information must be disseminated through informal as well as formal communication channels. However, constant expected profits and rapid rates of diffusion, with a classic S-shaped adoption curve, should not be expected for 1 arge-scale technologies with long lead times and socially controversial characteristics. Additional research on historical and current examples of 1 arge-scale, controversial technologies is needed to find appropriate forecasting technologies and effective management strategies.

Technology Transfer

Technology transfer is a crucial part of any government commercialization program. Technology must at some point be transferred from the government or contract laboratories to the firms or other government entities that will use the technology. It is absolutely essential to understand the factors that influence the success of this step in the commercialization process.

Our limited reading of this literature revealed that technology transfer is a complex and difficult process. Efforts at technology transfer of ten fail. Furash (1968) states that high expectations for the transfer of NASA technology to terrestrial private sector applications were widely disappointed. Cordell and Gilmour (1976) report a low rate of technology transfer from Canadian government research laboratories to the Canadian private sector. 
These studies suggest several reasons why the desired rate of technology transfer is not achieved. Furash reports that substantial adaptions of NASA technology were of ten required to make the technology practical in an earthly environment. In many cases, the adaptation costs were so high that firms either found it preferable to develop a terrestrial product independently rather than adapt NASA's exotic version or they simply chose to not venture into the area at all. Department of Defense (DOD) technologies often fail to be transferred to the civilian economy because DOD does not perceive any responsibility to transfer technology, and the agency makes no effort to do so (Furash 1968). Clearly, without specific agency mandates to transfer technology, offices within an agency responsible for transfer programs, and a technology whose stage of development and application environment are suitable, technology transfer does not happen very often because it is too expensive for the private sector participants.

The LWR commercialization program provides a bet ter example of technology transfer from the government to the private sector. In the LWR case, the agency had a clear mandate to transfer the technology. To meet this mandate, it developed a technology study program and a demonstration program (Perry et a1. 1977).

This limited example of studies indicates that frequently technology transfer does not occur because of the cost to the recipients or because govemment agencies are not really mandated and organized to carry out the technology transfer activities. In the process of organizing commercialization programs, the government can deal with the 1 atter but the cost constraint will always remain a stumbling block; however, it can be mitigated through tax and loan programs. Government commercialization programs need to consider both organizational and financial policies to facilitate the technology transfer aspects of commercialization.

The Implications of Market and Firm Structure for Commercialization

A considerable body of literature exists on the relationships between market and firm structure, and innovation. Market structure refers to the number of buying and selling firms in the market, their size, and other 
characteristics of the entire market. The literature focuses on the rel ationships between firms. Firm structure refers to the internal characteristics of firms: how many divisions they have, how many employees, and the extent of vertical and horizontal integration.

One focus of the market structure/innovation literature has been on innovation in monopolistic and competitive industries. A theoretical piece by Kenneth Arrow (1962) shows that competitive industries are more likely to adopt cost reducing innovations than monopolistic industries. Theoretical and empirical papers debating this proposition in the last 17 years indicate that the theoretical distinction between a monopolist's and a pure competitor's incentives to innovate does exist, but in practice their actual behavior may be very similar (Bownan 1977). Part of the reason for the absence of clearcut empirical evidence of different innovation patterns in existing monopolistic and competitive industries is that pure monopolists are seldom encountered. 01 igopolies are common, i.e., markets served by a small number of suppliers. Economic theory does not offer any clear distinction between the innovative incentives of oligopolists and those of pure competitors, and empirical evidence on the innovative performance of oligopolies has been mixed.

The work of Mansfield et a1. (1977) is a recent attempt to investigate real world market situations and innovation. This work is entirely empirical rather than theoretical. Mansfield et al. (p. 16) conclude that an industry with a mixture of firm sizes and some degree of market specialization is more likely to be technologically progressive than either an homogenous product, purely competitive, all small firm industry or an oligopoly composed of equalsized giants all producing the same product. Mansfield et al. also maintain that older firms with an established market and no significant competition tend to resist new technological ideas.

Magee (1977) argues that a highly concentrated industry structure contributes to high rates of investment in R\&D because a firm's ability to capture all of the returns to R\&D, or the "appropriability of the returns," increases if the firm controls a large proportion of the market. In a more competitive industry, R\&D conducted by one firm may lead to a new product or process that is quickly imitated by competitors. The innovating firm in these 
circumstances captures less of the potential profit associated with the innovation and has less incentive to perform the original R\&D. Magee's thesis has not been empirically tested, but, if valid, it clearly implies problems for government commercialization programs. The issues concerning the relationship between a firm's return on R\&D investment and the industry's structure deserve more empirical examination.

For commercialization, one of the most interesting findings of this body of literature pertains to effects of competition on the rate of development of inventions. Long time 1 ags between invention and innovation, or first actual use, are common. Nelson et al. (1967) observe that substantial investments are required to develop an invention into a useable process or marketable product. Industry structure may affect the rate at which this crucial development work is carried out. For inventions of small value, Kamien and Schwartz (1975) conclude that monopoly conditions will lead to the most rapid development. Competition could reduce the returns from the development and eliminate the incentives to carry out such development work. For inventions with large profit potentials, a moderate degree of competition seems to speed the development. Finally, monopoly power with respect to a current generation product tends to retard the development of subsequent generations of that product.

Another important and widely supported conclusion is that a threshold level exists for the performance of the R\&D in most industries. This threshold is at a moderate-size level in most industries. Very small firms do little or no R\&D work. At some level, of ten in the 1,000- to 5,000-employee size range in many industries, R\&D efforts are observed. At larger size levels, no more R\&D per unit of output is observed, with rare exceptions (Mansfield 1968 and Nelson et a1. 1967). Thus, very large firms tend to be less technologically progressive.

Government commercialization program planners need to be aware that if $R \& D$ is required to move government inventions into actual economic use, then the necessary development work is not likely to be performed by very small firms. On the other hand, it may also be somewhat frustrating to work with industrial giants. Moderately sized firms with R\&D capabilities are the most 
likely to have the motivation and the technical and financial capabilities to develop promising government-sponsored technologies. Very large-scale technologies, of course, strain the financial capabilities of moderately sized firms during the development stage leading to innovation.

Three implications of this literature are apparent for 1 arge-scale technology commercialization programs. First, it is not promising to aim commercialization efforts at particular parts of an industry given the state of knowledge about market structure and innovation. Moderately sized firms have an advantage because they can find receptive and motivated commercialization partners if development work is needed on a government-sponsored invention. However, it does not contribute to a diverse and dynamic industry to target moderately sized firms; large-scale technologies may also be beyond their capabilities. A policy of widespread dissemination of information and an effort to get a variety of different sizes and types of firms involved in a technology appear to be promising strategies.

Second, large-scale technologies tend to require massive investments by the supplying firms. Large firms may be needed to carry out such investments. The danger here is that the firms commercializing such a technology today will become the older, entrenched firms of tomorrow, who may then resist the next round of innovations. Advanced converter reactors may be an example of this tendency in the nuclear power industry. The predilection of the automobile industry for internal combustion engines provides another example. The danger of such entrenchment is clear, but policies to deal with it without compromising the original commercialization program are not so apparent.

Third, additional research is needed on the market structure of the industries in which commercialization programs are expected. The existing literature assumes that the process of technological change occurs entirely in the private sector. A full-scale commercialization program, in contrast, invoives the government in all stages of the process. Many of the market structure and innovation literature's findings need to be intensively reexamined with this government role in mind. The consequences of government involvement at the invention, innovation, and diffusion stages may be manifold. 
This involvement raises several questions: Do the types and sizes of firms that participate in such a program differ from what would occur in a private sector technological change process? Do government programs tend to "entrench" technologies, building barriers to subsequent private or public sector innovation? What are the consequences of commercialization programs for the internal structure of firms and the effect of modified structure on the performance of these firms? How do government licensing and patent policies affect the appropriability of the returns to R\&D investments, and what impact does this have on the willingness of firms to participate in commercialization programs?

\subsection{COMMERCIALIZATION OF LARGE-SCALE TECHNOLOGIES}

Much of the literature on comercialization does not specifically focus on 1 arge-scale technologies. "Large-scale" refers to process technologies embodied in very 1 arge plants where one plant can produce a large proportion of firm's output and possibly a significant proportion of the whole industry's output. Much of the literature reviewed does not focus on scale per se as a significant factor; although, a few studies offer some insights into the salience of this dimension. We focus on this issue in general below and then turn to the particular case of large-scale technologies in the electric power industry.

The scale of many technologies is so 1 arge in relation to total demand that only one or a few plants are needed for the entire country. A very small number of cormunication satellites are needed to facilitate long-distance telephone and television needs. Such satellites can replace large numbers of cable, microwave, and broadcast antennae facilities. A few 1 arge, integrated installations are capable of assembling most of the nation's civilian passenger aircraft.

Other technologies are "packaged" in units that are very large in relation to the output of firms in an industry. The nuclear power reactor is a good example of this phenomenon. Light water reactor (LWR) designers perceived potential economies of scale that could lead to plants in the 1,000 to 
1,300 MW range. In order to provide desired levels of reliability, utility systems of 10,000 to $15,000 \mathrm{MN}$ are required to absorb such units. Many U.S. utilities are not this 1 arge, so joint venture or pooling arrangements have been used to absorb these very $l$ arge generating units and to arrange construction financing.

The commercialization of technologies of this scale is a complex process. This process is a phenomenon that strains the limits of economists' understanding for several reasons. One problem is identifying how 1 arge-scale inventions and innovations originate. While economists may have something to say about demand-pull incentives for invention and innovation, as the above examples of large-scale technologies suggest, very new, state-of-the-art technology is often involved in large-scale projects and may often be of the fundamental breakthrough or technology-push variety. Economists cannot forecast fundamental breakthroughs, and studies of "natural trajectories" for technological push trends are in their infancy. However, some efforts at technological forecasting using both judgmental, quasi-objective, and modeling techniques have been made (see the journal Technological Forecasting for examples).

Another problem with our understanding of commercialization is that industry structures may be dramatically altered by the introduction of a large-scale innovation. Large-scale, as it is defined here, implies that the technology may be too big for existing firms or that a new firm will be formed to commercialize the technology. Joint ventures may result, a phenomenon that has seldom been dealt with in diffusion studies. (a) Alternatively, an entirely new industry may be involved in which a new firm may more or less monopolize the industry for some time. The IBM computer and Polaroid Land Camera are examples of this.

A third limit to economists' understanding of 1 arge-scale technology innovations is in the general theory area. Technological change theory is particularly ill-suited to the study of very large-scale technologies.

(a) See Sommers (1978) for one attempt to deal with joint-venture phenomena. 
Discontinuous production functions with 1 imited substitutibility of input factors are common within a current generation of technology. Capital costs are usually a very high proportion of total costs. The costs of moving to the next generation of technology, or a new production function, are difficult to predict. Learning curve phenomena are critical elements in predicting the characteristics of the next generation of technologies.

A few insights of the existing literature apply to the 1 arge-scale technology phenomenon. Large investments are required to put such a technology into $\mathrm{place}$. In the context of Mansfield's (1968) diffusion model, this requirement will tend to slow diffusion for a given level of expected profit. On the other hand, a major technological breakthrough, such as computers and nuclear power in the 1950s and 1960s, may lead to such high profit expectations that many firms will quickly enter the supplying industry and many potential users will begin to invest in the technology. Profit expectations must be high for rapid adoption to occur. For large-scale technology comercialization programs, capital costs and profit expectations are clearly two of the crucial variables that should be monitored and forecast.

In the large-scale technology case, there is a clear danger that once the technology is adopted both suppliers and users of the technology may become financially and technically cormitted to it to such an extent that the next round of innovation in the industry will be resisted. Advanced converter reactors that would conserve supplies of fissile fuel materials are one example. The diffusion of the oxygen furnace was slowed by the steel companies' cormitment to the older blast furnace technology. It is, of course, difficult to distinguish between undesirable entrenchment of a now older technology and the 1 ack of a perceived profit potential in the newer generation. The market structure literature does warn that entrenched firms with a dominant market share have a tendency to do lesS R\&D and to resist further innovation.

Large-scale technology transfer definitely calls for extensive personal interactions between the suppliers and the users of the technology. Both parties have to be involved in the design, construction, and operation of the plant. Additional technical expertise may have to be added to the user firm's 
staff. In the nuclear power generation example, nuclear engineers and technicians had to be hired by utilities, and long-term formal planning departments had to be created within each utility organization.

The necessarily close relationships between suppliers and users of 1 arge-scale, state-of-the-art technology result in a deterioration of the "boundaries" of firms on the two sides of the market. In such situations, competitive market structures are unlikely to emerge; instead, long-term cooperative, contractual arrangements are likely to result. Given this structural relationship, the small numbers bargaining theory of 0liver Williamson (1975) may be applicable and the X-inefficiency, or organizational-slack, theory of Leibenstein (1975) may also be relevant.

Additional research is needed within the theoretical frameworks of Leibenstein and Williamson to describe, find, and evaluate practical solutions to this market structure problem, which is inherent in 1 arge-scale technologies. A market environment tending towards small numbers bargaining and $X$-inefficiency requires careful attention by economists.

\subsection{LARGE-SCALE TECHNOLOGY AND THE ELECTRIC POWER INDUSTRY}

Magnetic fusion power is certain to be a large-scale, complex, capitalintensive, state-of-the-art technology when it is introduced to the market in the mid- or long-term future. All of the generic large-scale technology issues discussed above are relevant to this particular case. As a result of the commercialization of nuclear power reactors and of other technological and resulting structural changes in the electric power generation industry in the U.S., several studies have focused on this industry. We will first review studies of electric utility market structure and then turn to diffusion studies and examinations of nuclear technology development and comercialization.

Much of the interest of economists in the U.S. electric utility industry results from the unusual structure of the industry. Due to antitrust policies, pure monopolies are seldom encountered in this country unless they are closely regulated. Electric utilities, including the investor-owned utilities, are pure monopolies; they face competition only from the other energy sources 
available to consumers and industry in most areas of the U.S. In all but four states, the investor-owned utilities are regulated by state-level comissions that define standards of service and set retail rates that allow the regulated monopoly to earn a "fair rate of return." The fair rate of return is set at a level that the comission determines to be just high enough to allow the company to prosper and to attract needed new investment capital. A premi um for the economic risks faced by the utility is included in this fair rate of return.

This rate-setting process has been attacked by economists for giving the regulated firm a bias towards excessive growth rates and capital intensity. This bias occurs for two reasons. First, because the allowable rate of profit is fixed, the only way for the utility to increase total profits is to enl arge the rate base. Hence, regulated utilities may at tempt to grow faster than an unregulated firm in the same circumstances would. Second, because of the risk premium, the allowable rate of return may be higher than the rate that an unregulated monopolist would earn at the same level of output. Consequently, the regulated monopolist at the same level of output may choose a more capitalintensive generating technique than a nonregulated monopolist. The regulated monopolist may also choose a different level of output; in this case, no theoretical statement about the capital bias can be made. The capital bias effect is called the Averch-Johnson effect (Averch and Johnson 1962).

Empirical studies testing for the existence of the Averch-Johnson capital bias effect ( $A-J$ effect or $A-J$ hypothesis hereafter) have produced mixed results. Smith (1977) found the capital bias explanation appealing but did not perform rigorous tests of the A-J hypothesis. Courville (1974) and Spann (1975) found some support for such effects with more rigorous tests. Peck and Stoner's (1977) study also found weak support for a dynamic version of the A-J effect.

However, Joskow (1973) notes that in many cases in the 1960s utilities were not constrained by the allowable rates of returns set by comissions, due to regulatory $l$ ag and falling generating costs. In addition, Joskow and MacAvoy (1975) found that mid-1970s rates of return were too low for $A-J$ 
effects to occur. Thus, no convincing empirical evidence of $A-J$ effects has been found because the assumed condition of a binding rate-of-return constraint seldom exists in reality. The explanation for utilities' interest in nuclear power and other capital-intensive generating technologies must lie elsewhere, perhaps in the technological-push or demand-pull explanation previously discussed.

However, if rate-of-return constraints are binding on investor-owned utilities when magnetic fusion plants begin to diffuse through the industry, then utilities will have an added incentive to adopt the technology. The term "binding constraints" refers to a regulated investor-owned utility earning its al lowed rate of return and also having the ability to attract as much investment capital as it needs at that rate of return. Should these conditions apply (and go unchallenged by regul at ory comissions and public interest groups), fusion plants may diffuse more quickly than otherwise.

Power pooling is another aspect of the utility industry structure that is important to the comercialization of magnetic fusion power. (a) Because both the nuclear and the current generation of coal-fired generating plants are very 1 arge-scale, 1 arge integrated generating systems are needed to reduce the possibility of a blackout should one of these large units fail. Throughout the $1960 \mathrm{~s}$ and 1970s, the Federal Power Comission (b) also encouraged pooling as a general reliability-enhancing policy. A power pool consists of a group of utilities with integrated transmission networks and a central dispatch facility for routine operations of the entire pool. Less tightiy organized groupings of utilities, called coordinating groups and reliability councils, also have limited interconnections; they provide short-term emergency pooling services to their members.

(a) The following discussion of pooling relies on Sormers (1978, Chapter 3 ). (b) The responsibilities and staff of the Federal Power Commission were incorporated into the new Federal Energy Regulatory Comission and the Energy Regulatory Administration, both components of the Department of Energy, in 1977. 
Magnetic fusion power commercialization programs must take pooling organizations into account. The large scale of the fusion plants will require pooling arrangements. In addition, some pools, such as the North East Power Pool, play a long-term planning role in their areas, so commercialization programs must be integrated with these existing planning institutions.

0 ther aspects of industry structure and performance that have been examined by economists include the optimal firm size for innovation (Link 1978) and factors explaining R\&D expenditures (Del aney and Honeycutt 1976). Link found some support for an optimal firm size within the range of utility sizes currently observed; this finding implies that large utilities do no more R\&D per dollar of revenue than the "optimal size" firm. Delaney and Honeycutt found that expenditures on R\&D per dollar of revenue increased for R\&D performed by a utility company, but they also found a proportional relationship for R\&D performed outside the utility but paid for by it. These results raise questions about the optimal size finding of Link since no optimal size exists for R\&D performed outside the utility. An assessment of the importance of and the payoff from inside and outside R\&D would be necessary to integrate the findings of Link with those of Del aney and Honeycutt.

No final conclusion can be reached about the relationship of R\&D to firm size in the electric power industry from the studies reviewed. Based on the current state of knowledge, commercialization programs for this industry that require some $R \& D$ to transfer the government-developed technology to the industry cannot be appropriately targeted at any particular group of utilities.

Several studies of the diffusion of innovations in the electric power sector have been completed. Peck and Stoner (1977) studied 20 innovations in the generating and transmission technologies. They concluded that larger utilities are more likely to innovate than small ones and that smaller and more tightly regulated utilities delay adoption more than 1 arger or loosely regulated utilities. Gandara (1977) uses a survey of the utility industry to corment on the financial, regulatory, and other factors that the utilities considered in making nuclear power adoption decisions. Sommers (1978) asserts that S-shaped logistic diffusion models are inappropriate for LWR diffusion 
studies, due to rapidly changing economic circumstances during the diffusion process. An alternative model is proposed; it models the nuclear adoption decision as a probabilistic choice determined by utility size, pool size, uncertainty about capital costs and reliability, and the expected construction lead time.

The LWR commercialization process has been intensively examined in studies by Perry et al. (1977) at the Rand Corporation. In many respects, the LWR program is the prime example of the potential and the pitfalls of large-scale technology commercialization programs. For a summary of their work, see Perry et al. 1977. They note some pitfalls that fusion programs should be aware of including insufficient attention to the political and institutional aspects of demonstration programs, premature discontinuation of R\&D programs on alternative reactor designs, incorrectly estimating costs, and not paying attention to the complete fuel cycle, resulting in an incomplete and politically vulnerable cycle.

The results of this review of the commercialization literature indicate that electric power generation technology is so large in relation to the size of existing firms that an institutional and disequalibrium exists. Industry structure is likely to change relatively rapidly over time as more large-scale technologies, such as magnetic fusion plants, are introduced. Powerful predictions about probable diffusion patterns are not possible in this context, aside from the assertion that the structure of the industry is likely to change relatively rapidly in response to technological pressures and social responses to those pressures. To the extent that government-supported R\&D provides the impetus for new large-scale innovations, the government will have a very large influence on the future structure of the electric power industry.

The commercialization literature clearly recommends making cost estimations and early economic evaluations of commercialization programs. However, the LWR example illustrates that extensive analysis cannot resolve all of the significant economic uncertainties prior to widespread diffusion of the technology. Only the diffusion process itself and many years of operating experience are capable of resolving questions about a nuclear unit's reliability, 
safety, and lifetime generating costs. Large-scale technology commercialization programs must be designed around this inherent element of economic uncertainty and the public controversy that may accompany it. 


\section{TOPICS FOR FUTURE STUDY}

The process of commercializing fusion must start early in the engineering development phase even though the success or failure of commercialization efforts will only become evident after the technology is introduced into the economy. All evolving technologies present choices that are made possible by the degrees of freedom available to the engineer. Decisions are made about applications, processes, size, and complexity. Intelligent choices cannot be made without knowledge of the economic conditions and market preferences at the time of introduction. The ideal mode of planning, called cybernetic planning, involves both exploratory and normative exercises. In exploratory planning, an attempt is made to gauge the future capabilities of a technology, fusion in this case, from present knowledge of the physical processes. The preliminary design of commercial reactors and the planning for engineering development facilities are parts of this process. In normative planning, the needs of society are projected and alternative paths of development that could satisfy these needs are examined. The inputs to normative planning are market analyses, cost-benefit studies, and social perception surveys. In this sense, planning for RD\&D, which results in strategies for engineering development, is also planning for cormercialization.

Beyond the requirements for engineering development and comercial demonstration, the process of commercialization has its own long lead time elements. The time horizon for commercial use inhibits significant near-term investments by industry; however, there is a need to start building the industrial base we 11 before industry makes investments. Similarly, fusion will be injected into a regulatory environment that can either support or limit its effect. The body of regulations are created slowly and develop a momentum in the system that is hard to change. The stability of the regulatory environment and the incentives provided for the adoption of fusion depend in part upon the groundwork 1 aid in the near future.

The issues confronting fusion and the literature on cormercialization suggest a large number of areas of fruitful research. While most topics are 
relevant to fusion in a general way, only a few would have a direct impact on the design of the fusion program. The criterion suggested for choosing topics for study is that the results of a study should have a direct bearing upon near-term strategies and decisions. The criterion can be applied by determining the impact of the research on the following:

- the evolution of the technology toward applications through the conduct of the program (including program planning);

- the initiation of program elements requiring long lead times without which cormercialization would be precluded or hampered;

- justification of the program in the eyes of its sponsors or supporters and its continued funding toward long-term objectives.

With this criterion in mind, we suggest nine topic areas for further study; they are listed in Table 5.1. Two of the topics--public perception and industry participation in the fusion development program--are currently under study.

\section{TABLE 5.1. Proposed Topics}

1. Public perception of fusion

2. Industry participation in RD\&D

3. Regulatory requirements

4. Utilities in Year 2020

5. Justification of national need

6. Funding for comercial demonstrations

7. Joint planning with industry

8. Function of industrial contractors

9. Technology transfer

\subsection{PUBLIC PERCEPTION OF FUSION}

Public perceptions will have a crucial role in the process of cormercializing fusion technology. Various groups' views of the characteristics of a fusion system will influence R\&D expenditures, utility interest, and general public acceptance. Differences in perception can lead to public controversy 
and, in some cases, fruitless debate because the bases for these different perceptions of a technology are not clearly understood. Magnetic fusion power, as an alternative to other methods of generating electricity, must be acceptable to the public and also meet technical and economic goals. In fact, public perception of fusion today is likely to be unclear and not well formed. Research and development programs have to be sensitive to these perceptions. We need a method of predicting the perceptions that are likely to emerge as the fusion concept appears more frequently in the public energy discussions.

While fusion power has not yet been identified with nuclear power in the public conscience, it shares enough of the overt atiributes--scale, centralized power production, and radioactive materials--for the impact of public perceptions of nuclear power to be of concern. The virtual certainty of intervention by antinuclear interest groups in the construction and operation of nuclear plants has been a major factor in their uncertain economic environment (Montgomery 1979). Opponents have encouraged a climate of social unacceptability partly through the mass media and partly through the courts. For some, nuclear power has become the symbol of all the evils of an industrial society in the nuclear age: the threat of nuclear holocaust; unchecked economic growth and material consumption; wanton destruction of the environment; and distrust of the government, big businesses, big labor, and technology. What began as public concern for environmental protection has become a broad and polarized debate over social issues.

Maynard, Nealy, Hebert, and Lindell (1976) developed a method for gathering perceptions about a complicated technology, nuclear waste disposal, to assess emerging conflicts. This study successfully demonstrated that, when compared to members of the public, technology groups had very different perceptions of the relative importance of short-term versus long-term safety. The method used in Maynard et al. is appropriate for assessing the perceptions of fusion. Both fusion and nuclear waste disposal involve complex technologies that are not easily grasped, but that can be described by their ultimate characteristics. Both situations deal with technologies that have not yet 
been demonstrated and both concern a national goal, energy supply, about which people have well-developed attitudes and values.

The suggested study would identify the perceptions concerning fusion power that differ in key groups of the public and relate these differing perceptions to their potential for conflict in the comercialization of fusion technology. Second, the study would attempt to understand the bases of these perceptions, especially as they relate to values and attitudes about energy and the environment. The study could focus on two topics: 1) the perceptions of fusion in general, including perceived risks and benefits; and 2) the perception of fusion compared with perceptions of such alternatives as solar power and breeder reactors.

\subsection{INDUSTRY PARTICIPATION IN RD\&D}

The history of 1 ight water reactor (LWR) development, as a model for fusion, can be both instructive and somewhat misleading. It offers a successful example of early vendor involvement in a nuclear technology that was ultimate by commercialized. However, nuclear power was developed and introduced in an institutional environment that will have changed by the time fusion is introduced (Bupp 1978). Fusion planners must be sensitive to the differences between fusion and fission and the differences between the business environment and experience base of the 1950's and those that will face a future fusion industry (Energy Future 1979). Financial losses in early LWR turnkey plants and the sudden evaporation of the national commitment to the LMFBR, along with all the other cost and environmental problems that the fission industry has suffered, will make many industries reluctant to cormit private resources to the fusion program.

A number of key issues must be addressed before a context is created for industry involvement in fusion development and commercialization. First, the timing for vendor involvement must depend upon the relevance of that involvement to the technical program. In addition to shaping the technology to meet vendor and user needs, the fusion program must make the most effective use of government funds. Participation in the program must be early enough to effect 
the transfer of the technology to industry. Second, the nature of the involvement by industry--from R\&D contracts to cost and risk sharing--must be established. Government program managers need to understand why the various industries decide to become involved in fusion RD\&D and under what conditions companies will commit their top talent to government contracts, contribute time to fusion planning and studies, and/or directly fund fusion efforts. Fusion programs may potentially affect other corporate activities, such as other 1 arge-scale energy RD\&D programs. Last, there is a need to examine the incentives for business investments and risk sharing in the fusion program.

Corporate investment in fusion technology will be linked to utility interest in the adoption of fusion. In planning for their long-term energy future, utilities will decide which energy-generation options to pursue. The role and priority of fusion development will depend upon the utilities' investments in and comitments to LWR technology, the use of advance converter reactors, and the progression to breeding technology. The recent history of the HTGR and LMFBR demonstration programs has amply demonstrated the significant risks associated with nuclear technology commercialization. The fusion program should consider the conditions that will encourage utility interest in fusion and the roles that will promote utility investment in fusion development, demonstration, and comercial use.

\subsection{REGULATORY REQUIREMENTS}

The regulatory requirements for fusion are currently undefined. It appears that a study to identify all of the pertinent federal regulations that would apply to fusion and to explore the legal issues applicable to fusion technology would be useful. The study could also identify regulatory gaps and suggest credible mechanisms for filling those gaps without creating arbitrary and conflicting controls. Unless the interpretation of advanced reactors is amended or the definition of special nuclear materials is changed to include tritium, it appears that the Nuclear Regulatory Commisssion (NRC) does not have a mandate to regulate fusion power. Further, it is not clear that the NRC, as it is currently structured, would regulate fusion to maximize its 
potential as an energy source (Montgomery and Rose 1979). However, without federal legislation to regulate fusion at the national level, fusion would be subject to the plethora of conflicting regulations and agencies that operate at the state and $1 \propto a l$ level.

Under the Atomic Energy Act of 1954 and subsequent amendments, the authority for regulating nuclear power was placed in the hands of the Atomic Energy Camission (AEC); federal regulation thus superceded most regional regulation authorities. By the 1970's, the AEC's policies toward nuclear power had the appearance of promoting its supporters and harrassing its opponents. On the rationale that promoting and regulating nuclear power in a single agency was a conflict of interest, the two functions were separated and given to ERDA and the NRC, respectively. The conflict of interest was eliminated, but many other problems were created. Much of the uncertainty currently clouding the future of nuclear power is a result of the conflicting signals from the separate bureaucracies. Because there is no constructive dialogue between agencies and no central authority to resolve their differing positions, technical nuclear developments that might improve plant performance and that are in the public interest are not pursued out of fear that regulators will order retrofits all existing plants. The situation confronting fusion could well be the same unless new institutional arrangements are made.

The environmental regulation of fusion plants may very well fall to the Environmental Protection Agency (EPA). The EPA al ready regulates radiation exposure to the general public, pollutant discharges to the air and water, and solid and nonradioactive hazardous waste disposal. The proposed study of federal regulations could investigate the aspects of fusion that are likely to require environmental regulation and identify the regulatory body that should regulate fusion.

A variety of other 1 egal and regulatory issues are important to the application of fusion technology. Many of the issues are similar to the important issues in fission technology. These include, plant licensing, facility siting, liability issues, antitrust considerations, and safeguards considerations.

An environmental impact statement on the fusion program and for individual fusion facilities will probably be required prior to construction because 
of the National Environmental Policy Act of 1970. A programatic EIS is currently being produced at $O$ ak $R$ idge $N$ ational Laboratory.

\subsection{UTILITIES BY THE YEAR 2020}

The electric utilities were created to provide efficient and reliable service to the public. Government regulation was imposed to prevent both destructive and inefficient competition and the use of monopoly power. The utilities and regulations have both evolved in response to technological advances and perceived threats to the public. Nuclear power advances pushed the energy production frontier from a few hundred megawatts per plant to over 1000 megawatts. Decade-long construction schedules have prompted proposals for including construction work in progress in the rate base. The size of the financial comitments have forced smaller utilities to join in cooperative corporate ventures. The Northeast blackout of 1965 resulted in new institutions for power pooling and coordination. The utilities and the regulatory environment will continue to evolve, so fusion may be introduced in circumstances quite different from the current ones. Fusion must be developed to meet the structure of the utility industry as it will exist around the year 2020. It would be a mistake for engineers to consider only the current requirements. For instance, the 1 arge size of earlier fusion reactor designs created concern that no utility could afford to build a fusion plant. However, a recent study on the optimal size of fusion plants indicates that plants as 1 arge as 3000 to 4000 MWe may be acceptable (Deonigi and Fraley 1979). Because of the potential impact of the projected needs of the utilities on the fusion design choices that will be made in the near future, a study should be undertaken on the future structure of the utilities.

\subsection{JUSTIFICATION OF NATIONAL NEED}

Numerous studies have been conducted to determine the national need for energy technologies. The cost-benefit studies for the LMFBR have received the most attention and scrutiny. Without denying the value of measuring future benefits against the costs of development, these studies were unable to prove 
conclusively that the breeder is needed on the time schedule advocated by its program managers. The results after adjusting the input assumptions-particularly the electricity growth forecast and the discount rate--revealed returns that ranged from profits worthy of industrial investment down to negative returns on investments. Low rates of return on the investment cannot justify public investment any more than it can private investment. For the fusion program to enjoy the large public outlays required for many decades, some measure of national need must be demonstrated definitively.

The normal planning horizon for decision makers is determined by institutional factors--the term of office or the budget cycle. Fusion has to provide some measure of benefit in this context or its cost becomes a liability. This logic has led some advisers to suggest the need for more near-term applications of fusion. Many advisers have recommended the development of the fusionfission hybrid reactor to use the intense neutron flux from thermonuclear reactions.

Despite the difficulties in quantifying the national or personal benefits from fusion, fusion continues to enjoy a significant level of support, demonstrated by the size of the budget it enjoys. The exact motivation for the support is not understood, and our ability to justify fusion is limited until the reasons for its support are understood. Perhaps the vision of an ultimate and limitless fount of energy is the source. Maybe the nation must pursue fusion as insurance against the exhaustion of more conventional energy forms. Some answers will be provided by a study on the public perceptions of fusion. Other views have been expressed in support of the breeder reactor and may be applied to the fusion program (Hamester 1975).

Allison in The Essence of Decision (1971) presents three models for decision-making at the national level: 1) the rational actor model; 2) the bureaucratic process model; and 3) the governmental politics model. The rational actor model presents decision- and policy-making as rational choices that consist of value maximization within the context of a given utility function, fixed alternatives, and known consequences (in one of the three senses corresponding to certainty, risk, and uncertainty). Decision making consists of 
selecting the alternative with the highest utility for the decision maker. The AEC's choice of the LMFBR as the highest priority reactor program, as justified by cost-benefit studies, is an example. In the bureaucratic process model, decisions are the outputs of organizational processes. Existing organizational routines constitute the effective range of choices open to government leaders. Decisions are made by subdividing any complex problem into subproblems to be handled by separate organizational components. Value maximization is replaced by satisficing decisions made in the context of avoiding uncertainty. It is not hard to find evidence of the bureaucratic process model at work in government agencies. The model suggests that organizations can continue to pursue programs of significant level and duration in the absence of any real or perceived national support. The governmental politics model presents decisions as the results of political negotiation and compromise between officials with diverse interests and unequal influence.

However, decision makers at different points in the budgetary process operate with alternative criteria. Depending on the view point of the decision maker, what constitutes a "national need" will vary. Cost-benefit ratios, while very important to some actors, are meaningless to others if they do not accept the underlying asumptions of the cost-benefit analysis. Thus, for the fusion power program to maintain credibility throughout the budget process, the full range of objective arguements, both quantifiable and qualitative, must be considered.

\subsection{FUNDING FOR COMMERCIAL DEMONSTRATIONS}

Commercial demonstration projects stand at the junction of the federal development program and industrial investment in commercial reactors. Commercialization costs can be staggering, but Congress seeks significant industrial investments that may not be justified by normal business and financial criteria. Baer et al. (1976) in Analys is of Federally-Funded Demonstration Projects recommend cost and risk sharing between government and industry with their full participation in the management of the project. The Clinch River Breeder Reactor Project was initiated with cost sharing and joint public and 
industry management. Escalating costs so diminished the fraction of private investment that the government asserted a dominant role in the project. For this and other reasons, both private and public support for the project declined.

It will be many years before demonstration plant funding decisions must be made, and it may take as many years to find institutional mechanisms for effective cost and risk sharing by government and industry. New options are being pursued in the creation of a synthetic fuels industry (Ball 1979); the fusion program will benefit by the experience. Other options should also be examined and sound recommendations made. The experience of Japan and other countries may suggest innovative approaches (Holloman 1979). Without feasible institutional solutions, the funding of more near-term facilities could conceivably be jeopardized.

\subsection{JOINT PLANNING WITH INDUSTRY}

Most studies on commercialization recommend significant industry involvement in the planning for RD\&D (MCEachron 1978). Participation by industry promises industries the benefits of experience and exposes researchers to business attitudes and behavior. Participation is also one means of promoting the growth of a constitutency of industrial supporters that is so critical to a program of fusion's magnitude and duration. To protect the interests of the public, Congress has enacted legislation that may preclude effective private sector participation in planning (National Research Council 1978). The Freedom of Information Act and the Government in the Sunshine Act expose the deliberations of industry and government to public scrutiny. Proprietary information, often needed in order to make intelligent decisions, is perceived to be jeopardized. Advice from the industry may lack the directness and candor needed for effective planning because the laws and regulations governing patents and licenses place restrictions on industry with respect to both industrial-developed technologies and the commercial use of federally funded 
innovations. Joint planning presents questions of conflict of interest for industrial organizations. Moreover, joint planning could be interpreted as leading to restraint of trade under the antitrust statutes.

The general counsel of DOE can provide advice on these problems, and outside advice should be solicited from a wide range of sources to find a means of communication that will fulfill the needs of government program managers and satisfy the letter and spirit of the law. New institutions may be required, such as federally legislated, government-industry, trade associations. Creative thinking is essential in this area for fusion is to enjoy the full participation of industry.

\subsection{FUNCTION OF INDUSTRIAL CONTRACTORS}

Industrial participation in planning and private sector investments in RD\&D are certainly desired, but the predominant role of industry for many years will be as contractors for the DOE fusion program. As the program begins a transitition from research to engineering development, industry will take an increasing share of the program budget. The shift in emphasis must take into account the continuing program of research, pressure to fund more work by industry, pressure from an industry anxious to become part of the program, and pressure from legislators to promote private sector participation.

Program strategy and $\mathrm{plans}$ must clearly convey priorities on the content of the RD\&D program. The role of industry in various elements of the program should be defined and logically supported. A study is suggested to make policy recormendations on industry's role in the program.

\subsection{TECHNOLOGY TRANSFER}

An important ingredient in commercialization is the transfer of technical know-how from the government to the private sector. Much of this knowledge is held collectively in the national laboratories and universities and contained in the minds of physicists and engineers. Information is transferred through government contracts with industry, e.g., learning-by-doing, and through conferences and publications. Industrial research organizations use three 
general approaches to facilitate the utilization of research results. The most effective approach is person-to-person contact. The other approaches use procedural and organizational connections to permit interactions among individuals (Roberts 1978). Person-to-person contact is fostered by the movement of people from one setting to another, joint teams, and the geographical proximity of the sending and receiving groups. Nothing motivates technology transfer like enthusiasm, and enthusiasm can only be conveyed in contacts between people. Procedural approaches attempt to bridge the gaps between research groups and the groups using the research by such management interfaces as joint planning, joint funding, and joint appraisals of research projects. In industry, procedural approaches have fallen into disfavor. Joint funding tends to create expectations that are hard to fulfill, and without the commitment of resources from all parties, joint planning adds little to the transfer objective. Joint appraisals can be effective when all of the parties have a stake in the outcome, but they must be combined with project-related interactions at the working level. Organizational linchpins often bring together people and combine the goal structures of separate groups, effectively. In industry, new groups that combine marketing, financial, and engineering personnel are formed to develop a technology or product. Across companies or between government and industry, special organizations might be chartered to move a technology from the laboratory to commercial use.

As fusion begins to reach maturity, engineers and scientists in the national laboratories will begin to find new projects unless they are motivated to make the transition from the laboratory to the company developing fusion. Similarly, much of the culture and richness of fusion knowledge and technology contained in their heads will have to be relearned and reinvented in the private sector without experienced personnel from the laboratory. Policies and programs should be examined that would promote more contact at the working level between engineers on both sides of the technology transfer divide. Procedural and organizational connections that promote the transfer of the technology and, as a by-product, form a constituency of active and influential supporters might also be developed. 


\section{B IBL IOGRAPHY}

Abbott, L. F. 1978. Technological Development in Industry: A Survey of Social Aspects: A Survey of the Managerial, Organizational, and Wider Social Aspects of the Technological Development Process in Manufacturing Firms. Industrial Systems Research, Manchester, UK.

Abernathy, W. J., and J. W. Utterback. June/July 1978. "Patterns of Industrial Innovation," Technology Review, 80 (5):40-47.

Allison, G. T. 1971. The Essence of Decision: Explaining the Cuban Missile Crisis. Little, Brown, and Company, Boston, Massechusetts.

Arrow, K. J. 1962. "Economic Welf are and the Allocation of Resources for Invention" in The Rate and Direction of Inventive Activity. National Bureau of Economic Research, Princeton University Press, Princeton, N.J.

Ashworth, C. P. February 1976. "A User's Perspective of Fusion." Pacific Gas and Electric, San Francisco, CA, presented to Conference on Energy Development, Probing the Possible, Atomic Industrial Forum.

Ashworth, C. P. February 1977. "A User's Perspective of Fusion, Part II." Pacific Gas and Electric, San Francisco, $C A$, presented to Conference on Energy Development, Probing the Possible, Atomic Industrial Forum.

Averach, H. and L. L. Johnson. 1962. "The Behavior of the Firm under Regulatory Constraint." The American Economic Review, 52(5):1053-1069.

Baer, W, S., L. L. Johnson, and E. W. Merrow. May 27, 1977. "GovernmentSponsored Demonstrations of New Technologies." Science, 196(4293):950-957.

Baer, W. S., L. L. Johnson, and E. W. Merrow. April 1976. Analysis of Federally Funded Demonstration Projects: Final Report. Rand Corporation, Santa Monica, CA.

Ball, B. C. August/September 1979. "New Challenges to Management in the Synfuel Revolution." Technology Review, 81(8):34-35.

Baranson, J. 1977. "Risk Perception of Technology Decisions in Public Enterprises: A Framework for Further Research." Engineering Economics, $\underline{23}(1): 31-39$.

Berg, S. V. 1973. "Determinants of Technological Change in the Service Industries." Technological Forecasting and Social Change, 5:407-427.

Bezdek, R., et al. April 1977. Analys is of Policy Options for Accelerating Commercialization of Solar Heating and Cooling Systems. TID 27597, Report for Energy Research and Development Administration by The George Washington University, Behavorial Studies Group, Program of Policy Studies in Science and Technology, Washington, DC. 
Blaug, M. 1975. "Kuhn versus Lakatos, or Paradigms versus Research Programmes in the History of Economics." History of Political Economy, ㄱ( 4$): 399-433$.

Bodde, D. L. 1976. "Regul ation and Technical Evolution: A Study of the Nuclear Steam Supply System and Commercial Jet Engine." Unpublished DBA Thesis, Harvard University, Cambridge, Massechusetts.

Bowman, W. 1977. "The Incentive to Invent in Competitive as Contrasted to Monopolistic Industries." Journal of Law and Economics, 20(1):227-228.

Bradbury, F. R. January 1977. "Constraints to Innovation." Chemtech, Z $(1): 23-27$.

Bugos, B. J. 1976. The U.S. Supersonic Transport Program 1961-1971: An Examination in Search of Lessons for Current Energy Technology Commercialization Projects. MIT-EL 76-030WP, Report for U.S. Energy Research and Development Administration by Energy Laboratory, Massachusetts Institute of Technology, Cambridge, Massechusetts.

Bupp, I. C. and J. C. Derian. 1978. Light Water: How the Nuclear Dream Dissolved. New York Basic Books, Inc. New York, NY.

Carillo-Huerta, M. M. 1978. "Determinants of the Adoption of Agricultural Innovations." The American Economist, 22(2):50-55.

Charpie Task Force. February 1978. The Demonstration Project as a Procedure for Accelerating the Application of New Technology. DOE/RA-0003/1, Report for Department of Energy, Assistant Secretary for Resource Applications, Washington, DC.

Coates, J. F. June 1976. "Technology Assessment--A Tool Kit." Chemtech, $\underline{6}(6): 372-383$.

Coleman, J. S., E. Katz, and H. Menzel. 1966. Medical Innovation: A Diffusion Study. Bobbs-Merri11, Indianapolis, IN.

Colton, R. M. 1977. "Rejoinder to Government Policies for Technological Innovation by Robbins and Milliken." Research Policy, 6:241-251.

Camittee on Private Sector Participation in Federal Energy RD\&D P lanning. 1978. Private Sector Participation in Federal Energy RD\&D Planning. National Academy of Sciences, Washington, DC.

Cone, B. W., et al. March 1978. An Analys is of Federal Incentives Used to

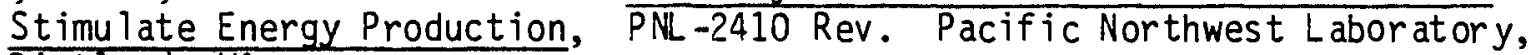
Richland, WA.

Corde11, A. J. and J. Gilmour. 1976. The Role and Function of Government Laboratories and the Transfer of Technology to the Manufacturing Sector. for Canada Background Study, No. 35, Science Council of Canada, Ottowa, Ontario. 
Courville, L. 1974. "Regulation and Efficiency in the Electric Utility Industry." The Bell Journal of Economics and Management Science, $\underline{5}(1): 53-74$.

Davies, H. 1977. "Technology Transfer Through Commercial Transactions." Journal of Industrial Economics, 26 (2):21-33.

DeBellis, R. J. March 1977. Utility Requirements for Fusion Power. EPRI ER-452-SR, Electric Power Research Institute, Palo ATto, CA.

dekluyver, C. A. 1977. "Innovation and Industrial Product Life Cycles." Cal ifornia Management Review, 26(2):161-175.

DeYoung, J. H. and J. E. Tilton. February 1975. Public Policy and the Diffusion of Technology: An International Comparison of Large Fossi 1Fueled Generating Units. Final Report to the Center for Policy Alternatives, Massachusetts Institute of Technology by College of Earth and Mineral Sciences, Pennsylvania State University, University Park, Pennsylvania.

Delaney, J. B. and T. C. Honeycutt. 1976. "Determinants of Research and Development Activity by Electric Utilities: Comment." The Bell Journal of Economics and Management Science, $\underline{7}(2): 722-725$.

Delaney, J. B. and T. C. Honeycutt. May 1976. An Empirical Analys is of Electric Utility Research and Development Activity. Antitrust and Indemnity Group, Office of Nuclear Reactor Regulation, U.S. Nuclear Regulatory Commission, Washington, DC.

Demsetz, H. October 1966. "Some Aspects of Property Rights," Journal of Law and Economics, $\underline{9}(2): 61-70$.

Demsetz, H. May 1967. "Toward a Theory of Property Rights," American Economic Review, 56(2):347-359.

Denning, R. S. et al. 1977. Fusion Power Development Issues. Report to the National Science Foundation by Battelle Columbus Laboratories, Columbus, Ohio.

Denny, J. E. 1978. "Federal Patent Policy - Its Development and Present Status" in Patent Policy: Government, Academic, and Industry Concepts, ACS Symposium Series 81, American Chemical Society, Washington, DC.

Deonigi, D. E. and D. W. Fraley. August 1979. Factors Affecting Potential Market Penetration of Laser Fusion Power Plants. PNL-2803. Pacific Northwest Laboratory, Richland, WA.

Dingee, D. A. April 2, 1979. "Fusion Power." Chemical and Engineering News. pp. $32-47$. 
Distributed Energy Systems in California's Future. May 1978. Interim Report Volumes I \& II prepared for U.S. Department of Energy by Lawrence-Berkeley and Lawrence Livermore Laboratories, and University of California at Berkeley and at Davis under Contract No. W-7405-ENG-48, Berkeley, CA.

Doctors, S. I. 1969. The Role of Federal Agencies in Technology Transfer. The MIT Press, Cambridge, MA.

Drucker, P. F. 1970. Technology, Management and Society. Harper \& Row, New York, NY.

Eads, G. and R. R. Nelson. 1971. "Governmental Support of Advanced Civilian Technology: Power Reactors and the Supersonic Transport." Public Policy, 29:404-427.

Eads, G. 1974. "U.S. Government Support for Civilian Technology, Economic Theory vs Political Practice," Research Policy, 3:2-16.

English, J. M. and J. L. Smith. January 1977. An Approach to Government/ Industry Investment Participation in Coal-Based Energy Projects. Econergy, Inc., Los Ange Tes, CA.

Eulberg, A. C. April 26, 1979. "Matching Government and Industry Perspectives on Energy Technology Commercialization." Public Utilities Fortnightly, 103(9):22-27.

Evenson, R. E. and Yoav Kislev. 1975. Agricultural Research and Productivity. Yale University Press, New Haven, Connecticut.

Executive Office of the President. June 1977. Directory of Federal Technology Transfer. U.S. Government Printing Office, Washington, DC.

Fisher, J. C. and R. H. Pry. June 1970. A Simple Substitution Model of Technological Change. 70-C-215, General Electric Research and Development Center, Schnectady, NY.

Frohman, A. L. 1978. "The Performance of Innovation: Managerial Roles." Cal ifornia Management Review, $20(3): 5-12$.

Furash, E. E. 1968. "The Problem of Technology Transfer." Raymond Bauer and Kenneth J. Gergen (eds.), The Study of Policy Formation. The Free Press, New York, pp. 281-328.

Fusfeld, A. R. May 1978. "How to Put Technology into Corporate Planning," Technology Review, $80(4): 51-55$.

Gandara, Arturo. 1977. Electric Utility Decisionmaking and the Nuclear Options. R-2148-NSF, NTIS: PB-283 962, Report for National Science Foundation by Rand Corporation, Santa Monica, CA. 
Gerstenfeld, A. 1977. Innovation: A Study of Technological Policy. University Press of America, Washington, DC.

Globerman, S. November 1975. "Technological Diffusion in the Canadian Tool and Die Industry." Review of Economics and Business, 57(4):428-434.

Gold, Bela. February 1977. "Analysing the Structure of Technological Impacts: From Physical to Economic Effects." Rivista Internazionale de Scienze Economiche e Commerciali, 24(2):100-126.

Gold, Bela (Ed.). 1975. Technological Change: Economics, Management and Environment. Pergamon Press, New York, NY.

Gold, Bela (Ed.). 1977. Research, Technological Change, and Economic Analysis. Heath, Lexington Books, Lexington, MA.

Griliches, Zvi. October 1957. "Hybrid Corn: An Exploration in the Economics of Technological Change." Econometrica, 25(4):501-522.

Haefale, W. et al. December 1976. Fusion and Fast Breeder Reactors. International Institute for Applied Systems Analysis, Laxenburg, Austria.

Hamblin, R. L., R. B. Jacobsen, and J. L. Miller. 1973. A Mathematical Theory of Social Change. Wiley \& Sons, New York, NY.

Hamester, H. C., G. A. Graves, and J. L. Plumer. 1975. "Risk Aversion and Energy Policy: A Case for Breeder Research and Development." Energy Systems and Policy, $1(3): 233-258$.

Harmon, A. J., A. J. Alexander, M. Davis, and A. D. Lee. November 1977. Technological Innovation by Firms: Enhancement of Product Quality. R-2237-NSF, Rand Corporation, Santa Monica, CA.

Heertje, A. 1977. Economics and Technical Change. Weidenfield \& Nicholson, London, UK.

Hirshberg, A. and R. Schoen, December 1974. "Barriers to the Widespread Utilization of Residential Solar Energy: The Prospects for Solar Energy in the U.S. Housing Industry." Policy Sciences, $\underline{5}(4): 453-468$.

Holdren, J. P. April 14, 1978. "Fusion Energy in Context: Its Fitness for the Long-Term," Science, 200:168-180.

Holdren, J. P. October 1977. "Environmental Aspects and The ir Systems Implications," Proceedings of EPRI Executive Seminar on Fusion. WS-77-16, San Franc isco, $\overline{C A}$.

Holland, S. (Ed.). 1976. Codes of Conduct for the Transfer of Technology: A Critique. Council of the Americas and Fund for Multinational Management Education, New York, NY. 
Holloman, J. H. et al. 1975. Energy Research and Development. Ballinger, Cambridge, MA.

Holloman, J. H. et al. May 1979. "Government and the Innovation Process." Technology Review, 81( 6$): 30-41$.

Holloway, F. A. L. 1978. "A View of the Government's Role in Energy Research and Development for the Civilian Sector." Energy Systems and Policy, 2(2): $145-157$.

Horwitch, M. and C. K. Prahalad. 1976. "Managing Technological Innovation-Three Ideal Modes." Sloan Management Review, 17(2):77-89.

Hough, G. W. 1975. Technology Diffusion: Federal Programs and Procedures. Lomond Books, Mt. Airy, MD.

Jolly, C. A. and J. W. Creighton (eds.). 1975. Technology Transfer in Research and Development. Naval Post-Graduate School, Monterey, CA.

Joskow, P. L. 1973. "Pricing Decisions of Regulated Firms: A Behavioral Approach." The Bell Journal of Economics and Management Science, 4(1):118-140.

Joskow, P. L. and Paul W. MacAvoy. 1975. "Regulation and the Financial Condition of the Electric Power Companies in the 1970's." American Economic Review, 65 (3):295-301.

Junta del Acuerdo de Cartagena. 1976. Technology Policy and Economic Deve lopment: A Summary Report on Studies Undertaken by the Board of the Cartagena Agreement for the Andean Pact Integration Process. International Development Research Centre, Ottowa, Ontario.

Kalt, J. P. 1978. "Technological Change and Factor Substitution in the United States: 1929-1967." International Economic Review, 19(3):761-775.

Kamien, M. I. and N. L. Schwartz. 1975. "Market Structure and Innovation: A Survey." Journal of Economic Literature, 13(1):1-37.

Kamien, M. I. and N. L. Schwartz. 1978. "Self-Financing of an R\&D Project." American Economic Review, 63(3):252-261.

Lacci, L. A., S. W. Davies, and R. F. Smith. 1974. "Tunnel Kilns in BrickMaking." L. Nasbeth and G. F. Ray (eds.), The Diffusion of New Industrial Processes: An International Study, Cambridge University Press, Cambridge, U.K. p. 105-145.

Lacy, A. W., R. C. Wilcox and R. I. Vachon. 1978. "Manufacturing in Outer Space: A One-Product Analys is." Quarterly Review of Economics and Business, $18(1): 7-18$. 
Laity, W. W. et a1. September 1979. Assessment of Solar Options for Smal1 Power System Applications, Volume 1. PNL-4000, Pac ific Northwest Laboratory, Richland, WA 99352.

Leibenstein, H. 1975. "Aspects of the X-efficiency Theory of the Firm." The Bell Journal of Economics, $6(2): 580-605$.

Lekva11, Per and Clas. Wahlbin. 1973. "A Study of Some Assumptions Underlying Diffusion Functions." Swedish Journal of Economics, 75(4):362-377.

Lewis, J. D. January 1977. "National Science and Technology Policy--Its Impact on Technological Change." Research Management, 20(1):13-16.

Linden; H. R. 1978. "Current Issues in U.S. Energy Policy with Special Reference to the Problems of Commercialization of New Technology." Energy Systems and Policy, 2(2):159-176.

Linhares, A. B. June 1976. An Overview of Federal Technology Transfer, NTIS PB-255 693, U.S. Department of Transportation, Washington, DC.

Link, A. N. 1978a. "Optimal Firm Size for R\&D Innovations in Electric Utilities." Journal of Economics and Business, 31(1):52-56.

Link, A. N. 1978b. "Rates of Induced Technology from Investments in Research and Development." Southern Economic Journal, 45(2):370-379.

Link, A. N. 1977. "On the Efficiency of Federal R\&D Spending: A Public Choice Approach." Public Choice, 31:129-133.

Linstone, H. A. and D. Sahal, (eds.). 1976. Technological Substitution: Forecasting Techniques and Application. American Elsevier, New York, NY.

Little, B. and R. G. Cooper. 1977. "The Role of Marketing Research in New Technology Ventures." Research Management, 20(1):20-25.

Lotker, M. November 1976. "Commercializing Fusion," International Meeting of the American Nuclear Society/European Nuclear Society, Washington, DC.

Lotker, M. January 1979. EPRI New Energy Resources Department Strategy Paper. EPRI ER-979. TPS 77-728. Electric Power Research Institute, Palo Alto, CA.

Magee, W. P. 1977a. "Application of the Dynamic Limit Pricing Model to the Price of Technology and International Technology Transfer." Journal of Monetary Economics, Supplementary Series 7 $2: 203-224$.

Magee, W. P. 1977b. "Multinational Corporations, the Industry Technology Cycle and Development." Journal of Wor ld Trade Law, 11(4):297-321. 
Manning, G. K. (ed.). 1974. Technology Transfer: Successes and Failures. San Francisco Press, San Francisco, CA.

Mansfield, E. 1968. Industrial Research and Technological Innovation: An Econometric Analysis. Norton \& Co. for Cowles Commission, Yale University, New York, NY.

Mansfield, E. et al. 1971. Research and Innovation in the Modern Corporation. Norton \& Co., New York, NY.

Mansfield, E. et a1. 1977. The Production and Application of New Industrial Technology. Norton \& Co., New York, NY.

Masson, R. T. December 1971. "Executive Motivations, Earnings, and Consequent Equity Performance," Journal of Political Economy, $\underline{79}(6): 1278-92$.

Maynard, W. S., S. M. Nealy, J. A. Hebert, and M. K. Lindell. 1976. "Public Values Associated with Nuclear Waste Disposal." BNWL-1997. Battelle Human Affairs Research Centers, Seattle, WA.

MCEachron, N. B., et al. September 1978. Management of Federal R\&D for Commercialization. SRI International, Men To Park, CA.

McFetridge, D. G. 1977. Government Support of Scientific Research and Development: An Economic Analysis. Ontario Economic Council Research Studies, No. 8, University of Toronto Press for the Ontario Economic Counc i1, Toronto, Ontario.

Mestre, E. R. and A. M. Lube11. 1975. "Mergers and Technological Change in the Garment Industry." Antitrust Bulletin, 20(3):521-542.

MIT Energy Laboratory Policy Study Group. November 1976. Government Support for the Commercialization of New Energy Technologies: An Analysis and Exploration of the Issues. Massachusetts Institute of Technology, Cambridge, MA.

Montgomery, T. L. and D. J. Rose. March/April 1979. "Some Institutional Problems of the U.S. Nuclear Industry." Technology Review, 81(5):53-62.

Montgomery, W. D. and R. G. Noll. October 1974. Public Policy and Innovation: Two Cases. (Social Science Working Paper No. 61), California Institute of Technology, Pas adena, CA.

Morr is, F. A. et al. 1978. Institutional Issues in the Development of Heliostat Manufacturing Capabilities. Battelle Mamorial Institute, Seattle, WA.

Myers, S. and E. E. Sweezy. March/April 1978. "Why Innovations Fail." Technology Review, 81 (5):41-46 
Nasbeth, L. and G. F. Ray (Eds.). 1974. The Diffusion of New Industrial Processes: An International Study. Cambridge University Press, London, UK.

Nason, H. K. 1977. "National Science and Technology Policy--Perceptions of Barriers to Innovation." Research Management, 20(1):17-20.

National Academy of Engineering, Committee on Technology Transfer and Utilization. 1974. Technology Transfer and Utilization: Recommendations for Redirecting the Emphas is and Correcting the Imbalance, PB-232 123, National Academy of Engineering, Washington, DC.

National Bureau of Economic Research. 1962. Rate and Direction of Incentive Activity, Princeton University Press, Princeton, NJ.

National Research Council, Commission on National Resources. 1978. Private Sector Participation in Federal RD \& D Planning. National Acadeny of Sciences, Washington, DC.

National Science Foundation, Office of National R\&D Assessment. 1973. Serving Social Objectives via Technological Innovation: Possible Near-Term Federal Policy Options. National Science Foundation, Washington, DC.

National Science Foundation, Office of National R\&D Assessment. 1975. Federal Technology Transfer: An Analys is of Current Program Characteristics and Practices. NSF 76-400, National Science Foundation, Washington, DC.

National Science Foundation, Office of National R\&D Assessment. 1976. Technological Innovation and Federal Government Policy. National Science Foundation, Washington, DC.

National Technical Information Service. 1976. Technology Transfer: General and Theoretical Studies. Department of Commerce, Springfield, VA.

Nelson, R. R. 1979. "Closer Integration of Science Policy and Economic Policy," Technology Innovation: Government/Industry Cooperation, A. Gerstenfeld and R. Brainard (eds.) Wiley-Interscience, New York, NY, pp. 196-205.

Nelson, R. R., M. J. Peck, and E. D. Kalachek. 1966. Technology, Economic Growth and Public Policy. The Brookings Institution, Washington, DC.

Nelson, R. R. and S. G. Winter. 1977. "In Search of Useful Theory of Innovation." Research Policy, 6:36-76. 
Nelson, R. R. and S. G. Winter. 1973. "Toward an Evolutionary Theory of Economic Capabilities." American Economic Review, 63(2):440-449.

Nemzek, T. A. and G. W. Cunningham. September 1974. "Current Status: The U.S. Fast Breeder Reactor Program." Proceedings of the International Conference on Advanced Reactors: Physics, Design and Economics. At lanta, Georgia.

Newberry, D. M. 1975. "Tenurial Obstacles to Innovation." Journal of Development Studies, $11(4): 263-277$.

No11, R. G. 1975. Government Policy and Technological Innovation: Where Do We Stand and Where Should We Go?. Social Science Working Paper No. 86, California Institute of Technology, Pasadena, CA.

Norris, K. and J. Vaizey. 1973a. The Diffusion of New Industrial Processes. George Allen \& Unwin, London, England.

Norris, K. and J. Vaizey. 1973b. The Economics of Research and Technology. George Allen \& Unwin, London, England.

O'Leary, R. 1978. "Clues for Product Innovators." Management Desision, $\underline{16}(4): 195-207$.

Paolillo, J. G. and W. B. Brown. March 1978. "How Organizational Factors Affect R\&D Innovation." Research Management, 21(2):12-15.

Pavitt, K. and W. Walker. 1976. "Government Policies Towards Industrial Innovation: A Review," Research Policy, 5:11-97.

Peck S. C. and R. D. Stoner. May 1977. The Diffusion of Technological Innovations Among Privately Owned Electric Utilities, 1950-1975. Report prepared for the National Science Foundation (Grant No. RDA 7516422), University of California, Berkeley, CA.

Perry, R. et al. June 1977. Development and Commercialization of the Light Water Reactor, 1946-1976. R-2180-NSF, the Rand Corporation, Santa Monica, CA.

Prescott, E. C. and M. Visscher. Autumn 1977. "Sequential Location Among Firms with Foresight," Bel1 Journal of Economics, $8(2): 378-393$.

Pry, R. H. 1973. Forecasting the Diffusion of Technology. 73 CRD 220, General Electric Company, Corporate Research and Development, Schenectady, NY.

Rappaport, J. 1978. "Diffusion of Technological Innovation Among Nonprofit Firms: A Case Study of Radioisotopes in U.S. Hospitals." Journal of Economics and Business, 30(2):108-118. 
Rhee, Y. W. and L. E. Westphal. 1977. "A Micro-Econometric Investigation of Choice Technology." Journal of Development Economics, 4 (3):205-237.

Robbins, M. D., C. A. Burke, and J. G. Milliken. 1973. Federal Incentives for Innovation: A Discussion of the Technological Innovation Process and a Presentation of Possible Federal Policy Options for the Stimulation of Innovation in Private and Public Sectors. Report to National Science Foundation, Office of Experimental R\&D Incentives, by University of Denver Research Institute, Denver, CO.

Roberts, E. B. March/Apri1 1978. "Strategies for Improving Research Utilization." Technology Review, 80(5):33-39.

Roberts, E. B. November 1978. "What Do We Really Know About Managing R\&D?" Research Management, $21(6): 6-11$.

Roberts, E. B. and A. L. Frohman. March/April 1978. "Strategies for Improving Research Utilization." Technology Review, 80(5):32-39

Rockwood, A. D. and T. L. Willke. October 10, 1978. "Commercialization of Large Scale Energy Technologies." Speech at the Fifth Annual University of Missouri-Rolla Conference on Energy, Rolla, MO.

Rolph, E. 1977. Regulation of Nuclear Power: The Case of the Light Water Reactor. R-2104-NSF, the Rand Corporation, Santa Monica, CA.

Rose, D. J. and M. Feirtag. December 1976. "The Prospect for Fusion." Technology Review, 79(2):21-43.

Rosenberg, N. 1975. "Problems in the Economist's Conceptualization of Technological Innovation." History of Political Economy, $I(4): 456-481$.

Rothwe11, R., J. Townsend, M. Teubal, and P. Spiller. 1977. "Some Methodological Aspects of Innovation Research." OMEGA, 5:415-424.

Russe11, L. B. 1977. "The Diffusion of Hospital Technologies: Some Economic Evidence." Journal of Human Resources, 12(4):482-502.

Ryan, B. and N. C. Gross. 1943. "The Difflision of Hybrid Seed Corn in Two Iowa Communities." Rural Sociology, $\underline{8}(1): 15-24$

Samue 1son, P. R. 1976. The U.S. Government Synthetic Rubber Program 1941-1955: An Examination in Search of Lessons for Current Energy Technology. Working Paper MIT-EL 76-027 WP, Massachusetts Institute of Technology, Cambridge, Massechusetts.

Sands, S. and K. M. Warwick. 1977. "Successful Business Innovation: A Survey of Current Professional Views." California Management Review, 20(2):5-16. 
Schnee, J. E. 1977. "Space Program Impacts Revisited." California Management Review, 20(1):62-73.

Scherer, F. M. 1970. "Industrial Market Structure and Economic Performance," Rand McNally, Chicago, Illino is.

Schoen, R., A. S. Hirshberg, and J. M. Weingart. 1975. New Energy Technologies for Buildings and Institutional Problems and Solutions. Ballinger, Cambridge, MA.

Schuller, C. R. et al. August 1976. The Legal, Institutional, and Political Problems in Producing Electric Power from Geothermal Energy in California. Battelle, Human Affairs Research Centers, Seattle, WA.

Slick, W. T., Jr. March 1976. "Comercialization of New Energy Technology," Proceedings of the Third Energy Technology Conference, Government Institute, Inc., Washington, DC.

Smith, B. A. 1977. Technological Innovation in Electric Power Generation 1950-1970. MSU Public Utility Papers, Michigan State University, East Lansing, Michigan.

Sommers, P. 1978. The Diffusion of Nuclear Power Generation in the United States. Ph.D. Dissertation, Yale University, New Haven, Connecticut.

Sommers, P. and R. W. Clark. 1977. ERDA and the Diffusion of Innovations. C00-4287-5, Institution for Social and Policy Studies, Yale University, New Haven, Connecticut.

Spann, R. M. 1974. "Rate of Return Regulation and Efficiency in Production: An Empirical Test of the Averch-Johnson Thesis." The Bell Journal of Economics and Management Science, $\underline{5}(1): 38-52$.

Stobaugh, R. and D. Yergin (eds). 1979. Energy Future. Random House, New York, NY.

Stokes, C. A. August/September, 1979. "Synthetic Fuels at the Crossroads." Technology Review, 81 (8):24-35.

Stoneman, P. 1976. Technological Diffusion and the Computer Revolution: The UK Experience. Cambridge University Press, London, England.

Teece, D. J. 1979. "Integration and Innovation in the Energy Markets." Advances in the Economics of Energy and Resources, Vol. 1: The Structure of Energy Markets, R. S. Pindyck (ed.), JAI Press, Greenwich, CT, pp. 163-212.

Teece, D. J. 1977. "Technology Transfer by Multinational Firms: The Resource Cost of Transferring Technological Know-How." Economic Journa?, 87 (346):242-261. 
Teubal, M. 1976. "Threshold R\&D Levels in Sectors of Advanced Technology." European Economic Review, 7(4):395-502.

Toevs, A. L. January 1978. "Technical Change in Manufacturing Industries Using Natural Resource Products." Southern Economic Journal, $44(3): 526-541$.

Tushman, M. L. December 1977. "Special Boundary Roles in the Innovation Process." Administrative Science Quarter ly, 22:587-605.

Wenk, E. March 1975. "Technology Assessment in Public Policy: A New Instrument for Social Management of Technology." Proceedings of the IEEE, $\underline{63}(3): 371-379$.

Wenk, E. and T. J. Kuehn. January 20, 1977. Technological Institutions and Networks. Unpublished Manuscript, University of Washington, Seattle, and Jet Propulsion Laboratory, Pasadena, CA.

Westfield, F. M. 1971. "Innovation and Monopoly Regulaton." Technological Change in Regulated Industries, William M. Capron (ed.), The Brookings Institution, Washington, DC, pp. 13-43.

Willke, T. L. et al. September 21, 1978. "A Plan for the Development and Commercialization of Inertial Confinement Fusion." Heavy Ion Fusion Conference, Argonne National Laboratory, Chicago, IL.

Windus, M. L. 1973. Regulatory Influences on Technological Innovaton. National Science Foundation, Office of National R\&D Assessment, Washington, DC.

Windus, M. L. and D. D. Schiffel. April 1976. "Recoupment of Government R\&D Expenditures: Issues and Practices in the U.S.A." Research Policy, 5: $180-196$.

Wolkenhauer, W. C. 1977. "Interface of Controlled Nuclear Fusion Programs with Utilities," Mimeo, Washington Public Power Supply System, Richland, WA 99352.

Yapor, L. S. and R. C. Mayfield. April 1978. "Non-Adoption of Innovations: Evidence from Discriminant Analysis." Economic Geography, 54(2):145-156.

Young, Mary E. (ed.). 1976. Technology Transfer: General and Theoretical Studies, A B ibliography with Abstracts. NTIS:PS-76/1008, Department of Commerce, Washington, DC. 



\section{DISTRIBUTION}

No. of

Copies

\section{OFFSITE}

$$
\begin{aligned}
& \text { A.A. Churm } \\
& \text { DOE Patent Division } \\
& 9800 \text { S. Cass Avenue } \\
& \text { Argonne, IL } 60439
\end{aligned}
$$

25 Gene R. Nardella

Reactor Systems and Applications Branch Office of Fusion Energy

Mail Stop G-234

(Germantown Headquarters)

Washington, DC 20545

27 DOE Technical Information Center

Hans L. Hamester

Donovan, Hamester \& Rattien

1055 Thomas Jefferson St., NW

Suite 414

Washington, DC 20007

Michae1 Lotker

1007 Broadmore Circle

Silver Springs, MD 20904
No. of

Copies

Paul Sommers

Human Affairs Research

Centers

4000 N.D. 41st Street

P.0. Box 5395

Seattle, WA 98105

Molly Selvin

Human Affairs Research

Centers

4000 N.D. 41st Street

P.0. Box 5395

Seattle, WA 98105

\section{ONSITE}

DOE Richland Operations Office

$$
\text { H.E. Ramson }
$$

34 Pacific Northwest Laboratory

D.E. Deonigi

D.A. Dingee

L.H. King

A.D. Rockwood (10)

L.D. Williams

T.L. Willke (10)

Economics Library (3)

Publishing Coordination (2)

Technical Information KE (5) 
